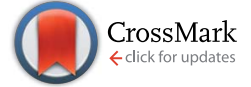

Cite this: Nat. Prod. Rep., 2015, 32, 1541

Received 13th May 2015

DOI: 10.1039/c5np00059a

www.rsc.org/npr

\section{Iron-promoted C-C bond formation in the total synthesis of natural products and drugs}

\author{
Julien Legros ${ }^{\star a}$ and Bruno Figadère ${ }^{\star b}$
}

Covering: up to 2015

Iron salts are inexpensive and almost innocuous; they are thus the promoters of choice, even in stoichiometric amounts, for the formation of carbon-carbon bonds in the backbone of complex molecules. This review encompasses the key role of iron complexes in the total synthesis of some natural products or pharmacologically important compounds.
1. Introduction

2. Cross-coupling reactions of organometallic reagents

2.1 With alkenyl and alkynyl (pseudo)halides

2.2 With aryl (pseudo)halides

2.3 With alkyl (pseudo)halides

2.4 With acyl chlorides

2.5 Ring opening

3. Lewis acid catalysis

4. Carbocyclisation

5. $\mathrm{C}-\mathrm{H}$ activation

6. Conclusions

7. Acknowledgements

8. References

\section{Introduction}

Iron (Fe) is the fourth most abundant element in the Earth's crust, and most of this iron is found as iron oxides, such as the minerals hematite $\left(\mathrm{Fe}_{2} \mathrm{O}_{3}\right)$ or magnetite $\left(\mathrm{Fe}_{3} \mathrm{O}_{4}\right) \cdot{ }^{\mathbf{1}, 2}$ For the biologist, iron is an essential element to most living beings, from single-celled microorganisms to humans, as illustrated for example by the Fe-containing protein hemoglobin. ${ }^{3}$ However, for the synthetic chemist, iron salts are often intimately connected to the centenarian Friedel-Crafts reaction, an electrophilic aromatic substitution promoted by metal salts, often including $\mathrm{FeX}_{3}(\mathrm{X}=\mathrm{Br}, \mathrm{Cl}) .{ }^{4}$ Recently, iron complexes have found increasing application in organic synthesis, especially as catalysts. Indeed, metal-catalysed reactions are essential utensils in the toolbox of the synthetic chemist, and only those combining criteria of efficiency, selectivity and reliability with

${ }^{a}$ COBRA UMR 6014 Normandie Univ, Univ Rouen, INSA Rouen and CNRS 1 rue Lucien Tesnière, 76821 Mont-Saint-Aignan, France.E-mail: julien.legros@univ-rouen.fr

${ }^{b}$ CNRS, BioCIS UMR 8076 Labex LERMIT, Univ Paris Sud, and CNRS 5 rue J. B. Clément, 92296 Châtenay-Malabry, France.E-mail: bruno.figadere@u-psud.fr cost effectiveness and low toxicity shall hold a prominent position in the future..$^{5-8}$ In this demanding context, iron occupies a place that probably no other transition metal can dispute: it is truly inexpensive and most of its salts exhibit low toxicity and they are generally environmentally benign. A comparison between iron salts $\left(\mathrm{Fe}(\mathrm{acac})_{3}, \mathrm{FeCl}_{2,3}\right)$, and some commonly used metal salts $\left(\mathrm{AlCl}_{3}, \mathrm{CuCl}_{2}, \mathrm{NiCl}_{2}, \mathrm{CoCl}_{2}, \mathrm{PdCl}_{2}\right)$ is given in Table 1.

Thus, iron complexes are by far the least expensive ones, with poor toxicity, environment poisoning or CMR classification (carcinogenic, mutagenic or toxic for reproduction). Only aluminium chloride is cheaper with higher $\mathrm{LD}_{50}$ and $\mathrm{LC}_{50}$ but it exhibits teratogenicity effects. Therefore, even when used in stoichiometric amounts, iron salts remain cheaper and safer that many other catalytic metal complexes, such as the palladium ones, broadly used in cross-coupling reactions. These decisive advantages make iron complexes the promoters of choice (under catalytic or even stoichiometric amounts) for elegant $\mathrm{C}-\mathrm{C}$ bond formation, as required to build the carbon backbone of poly-functionalized molecules in the total synthesis of natural products and bioactive ingredients. This review thus aims at illustrating how iron salts play a key role in carbon skeleton buildings in the total synthesis of natural products or pharmacologically important compounds (Fig. 1).

\section{Cross-coupling reactions of organometallic reagents}

Metal-catalysed cross-coupling reactions constitute one of the most straightforward and strongest methodologies to form $\mathrm{C}-\mathrm{C}$ bonds. ${ }^{9}$ In 1971 Tamura and Kochi reported for the first time successful and stereoselective examples of formal nucleophilic substitution between alkyl magnesium bromides and vinyl bromides in presence of very low catalytic loadings of $\mathrm{FeCl}_{3}$ in THF (Scheme 1). ${ }^{10,11}$ However, one year later Kumada and Corriu 
Table 1 Comparison of various metal salts

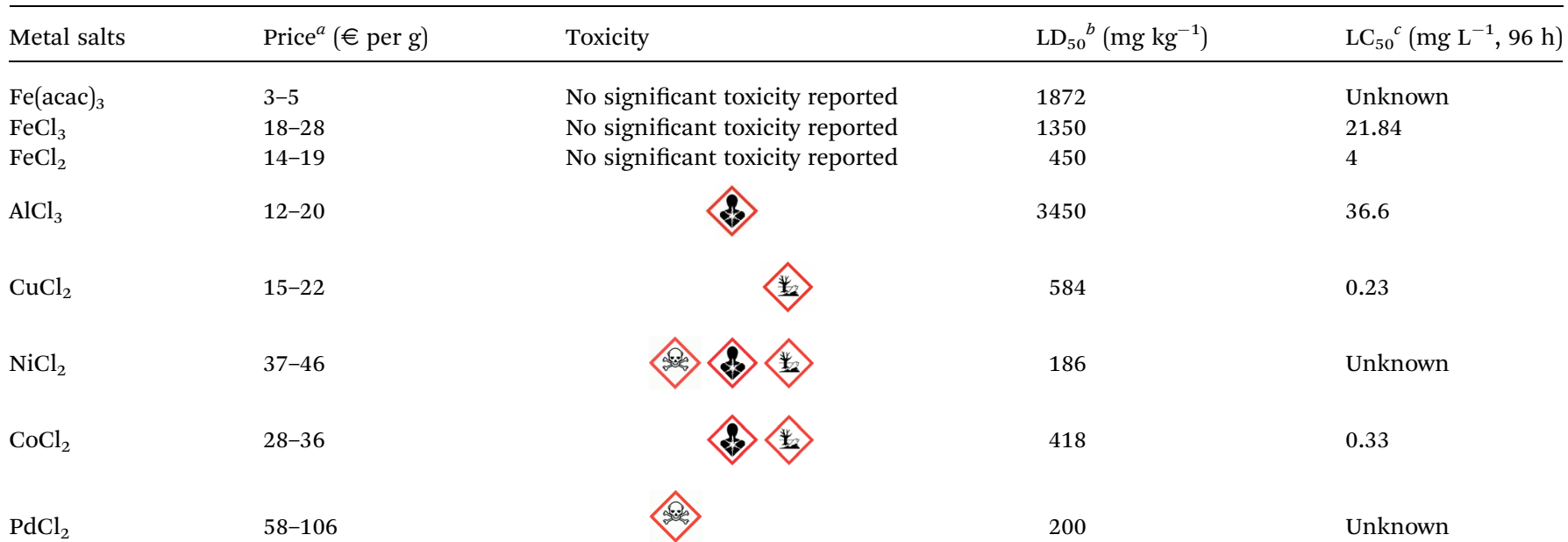

${ }^{a}$ Average range price for metal complexes with purity $\geq 99.9 \%$ taken from different providers. ${ }^{b}$ Lethal dose. ${ }^{c}$ Lethal concentration.

independently reported the cross-coupling reaction between Grignard reagents and organic halides by means of nickel catalysts, later extended to palladium complexes, and these transformations were then extensively studied leading eventually to the Nobel prize in 2010 to Negishi, Heck and Suzuki. The potential of Fe-catalysed cross-couplings remained in the shadow of palladium catalysis for many years and did not undergo much studies until Cahiez reported in 1998 a spectacular improvement allowing poorly reactive substrates, such as alkenyl chlorides, to be efficiently converted by using $\mathrm{Fe}(\mathrm{acac})_{3}$ as catalyst and $\mathrm{N}$-methylpyrrolidinone (NMP) as cosolvent; the yield jumped then from $5 \%$ in THF to $85 \%$ in this solvent mixture (Scheme 2). ${ }^{12}$

Therefore, methodology in Fe-catalysed cross-coupling reactions has met outstanding improvements, notably by Fürstner and Nakamura. Thus, the reaction scope has been extended to various
Grignard reagents and numerous electrophilic partners such as vinyl-, aryl- and alkyl (pseudo)halides. Moreover, many efforts have also been devoted to the comprehension of the reaction mechanism. Whereas Kochi early suggested the formation of an active "reduced form of soluble iron" generated from organomagnesium reagents and iron chloride, ${ }^{11}$ recent experimental and theoretical investigations suggest that the nature of the active iron species generated from either $\mathrm{Fe}(\mathrm{III})$ or $\mathrm{Fe}(\mathrm{II})$ and Grignard reagents depends on the nature of the latter (e.g. Ar- or alkyl-MgBr, presence of a hydrogen atom in the $\beta$-position). ${ }^{13-18}$ To briefly summarize, two main pathways are generally considered: double-electron transfer or single-electron transfer mechanisms. ${ }^{6,19}$

Iron-catalysed coupling reactions with organometallics, such as Grignard reagents, have shown their great compatibility with various functional groups and it is then not surprising that they have then been frequently applied as a key step in total

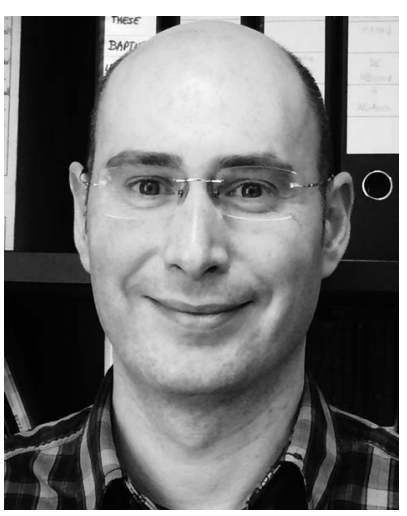

Julien Legros was born in 1974 and educated at the Universities Paris East, and then Paris South-Faculty of Pharmacy where he received his $P h D$ under the guidance of Dr D. BonnetDelpon and J.-P. Bégué (2002). After an Alexander von Humboldt post-doctoral position on iron catalysis with Prof. C. Bolm at the RWTH University (Aachen, Germany), he got a permanent position at the CNRS in 2004 (Univ Paris South-Faculty of Pharmacy) and then moved to the University of Rouen in 2011. Julien Legros is involved in synthetic methodology in non-conventional media (flow microreactors, hyperbaric conditions, fluorous solvents).

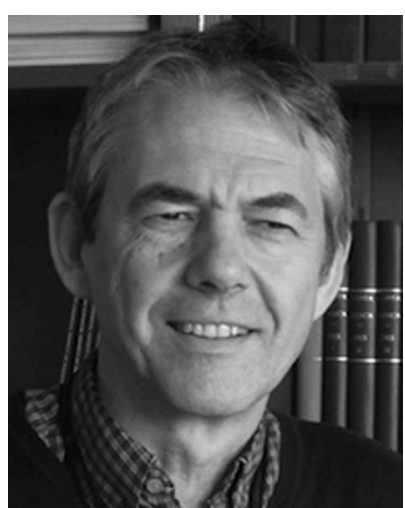

Bruno Figadère, born in 1960, was educated in Paris (University Pierre et Marie Curie) where he received his $P h D$ under $\operatorname{Dr} G$. Cahiez leadership. After a postdoctoral position at the University of California at Riverside with Prof W. H. Okamura (19881990) he got a permanent position at the CNRS and since then works at University of Paris SudFaculty of Pharmacy. He is currently director of the BioCIS

laboratory. Bruno Figadere is involved in the chemistry of natural products, especially in total synthesis, pharmacomodulation and characterisation of new bioactive compounds from different origins. 


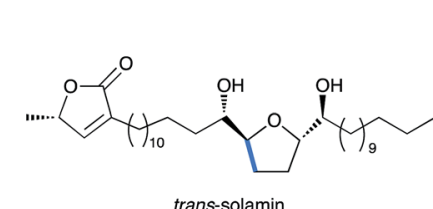

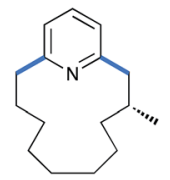

(R)-muscopyridine

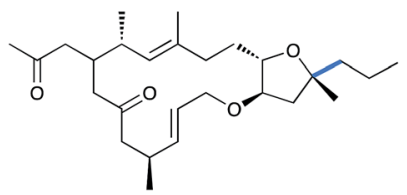

amphidinolide X

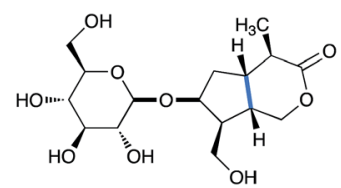

(-)-gibboside

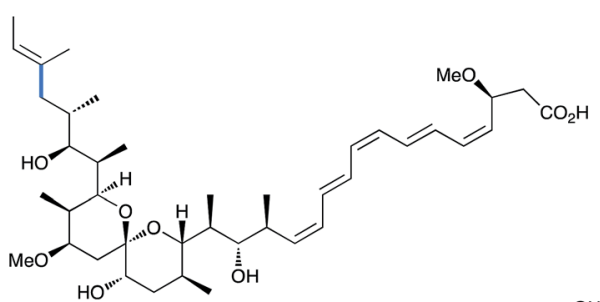

spirangien A<smiles>COc1cc([C@H]2c3cc4c(cc3C(O)C3COC(=O)[C@@H]32)OCO4)cc(OC)c1OC</smiles>

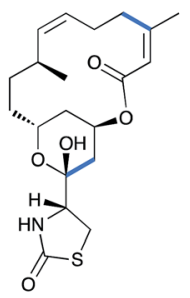

latrunculin B (+)-allokainic acid

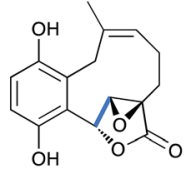

clavilactone A

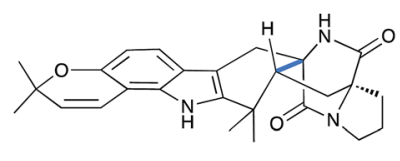

(-)-stephacidin A
Fig. 1 Some relevant examples of natural products synthesized through a Fe-promoted key step (highlighted in blue).

$$
\mathrm{MeMgBr}+\mathrm{Br} \curvearrowright \frac{\mathrm{FeCl}_{3}(0.12 \mathrm{~mol} \%)}{\mathrm{THF}, 0^{\circ} \mathrm{C}} \mathrm{Me} \curvearrowright
$$

$83 \%$

Scheme 1 First Fe-catalysed cross-coupling reaction with a Grignard reagent by Tamura and Kochi (1971).

$$
\begin{gathered}
\mathrm{BuMgCl}+\mathrm{Bu} \mathrm{Bu}_{\mathrm{Bu}} \underset{-5^{\circ} \mathrm{C} \text { to } 0{ }^{\circ} \mathrm{C}, 15 \mathrm{~min}}{\mathrm{Fe}(\mathrm{acac})_{3}(0.1 \mathrm{~mol} \%)} \\
\text { THF/NMP (9 equiv): } \mathbf{8 5 \%}
\end{gathered}
$$

Scheme 2 Improved conditions for Fe-catalysed cross-coupling with a Grignard reagent by Cahiez (1998).

syntheses of natural products and/or compounds of pharmacological interest, due to the ease, chemo- and stereoselectivity of the processes. ${ }^{5,8,20,21}$

\subsection{With alkenyl and alkynyl (pseudo)halides}

Aryl and alkyl Grignard reagents have been involved with various alkenyl and alkynyl electrophilic partners.

Alkenyl and alkynyl halides. Since the pioneering work of Kochi, vinyl halides have been widely used. For example, ironcatalysed coupling reaction of an homoallylic Grignard reagent 1 with a (Z)-bromoalkene 2 proceeded with complete maintaining of the geometry and led to a key diene 3 of defined $Z, E$ configuration $(70 \%$ yield), which after chemo- and enantioselective dihydroxylation will lead to cis and trans solamins, depending on the dihydroxylation procedures, two annonaceous acetogenins with cytotoxicity activity (Scheme 3$)^{22}$

A (Z)-bromoalkene 5 has also been coupled under iron catalysis to an aryl Grignard reagent 6 to afford combretastatin-

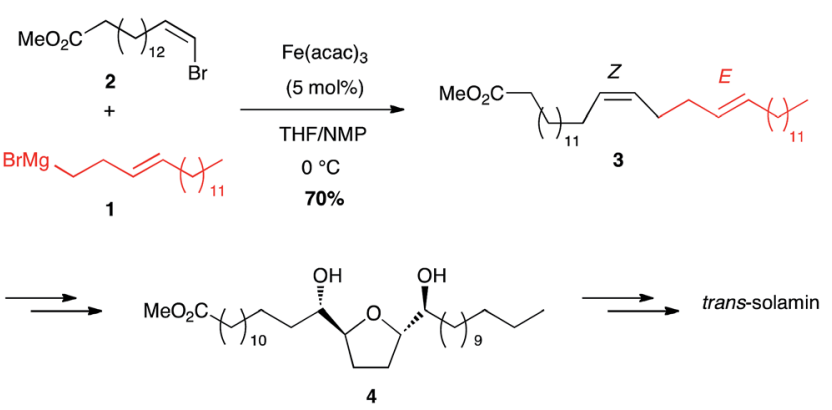

Scheme 3 Fe-catalysed cross-coupling of homoallylic magnesium bromide with a (Z)-bromoolefin for the synthesis of trans-solamin.

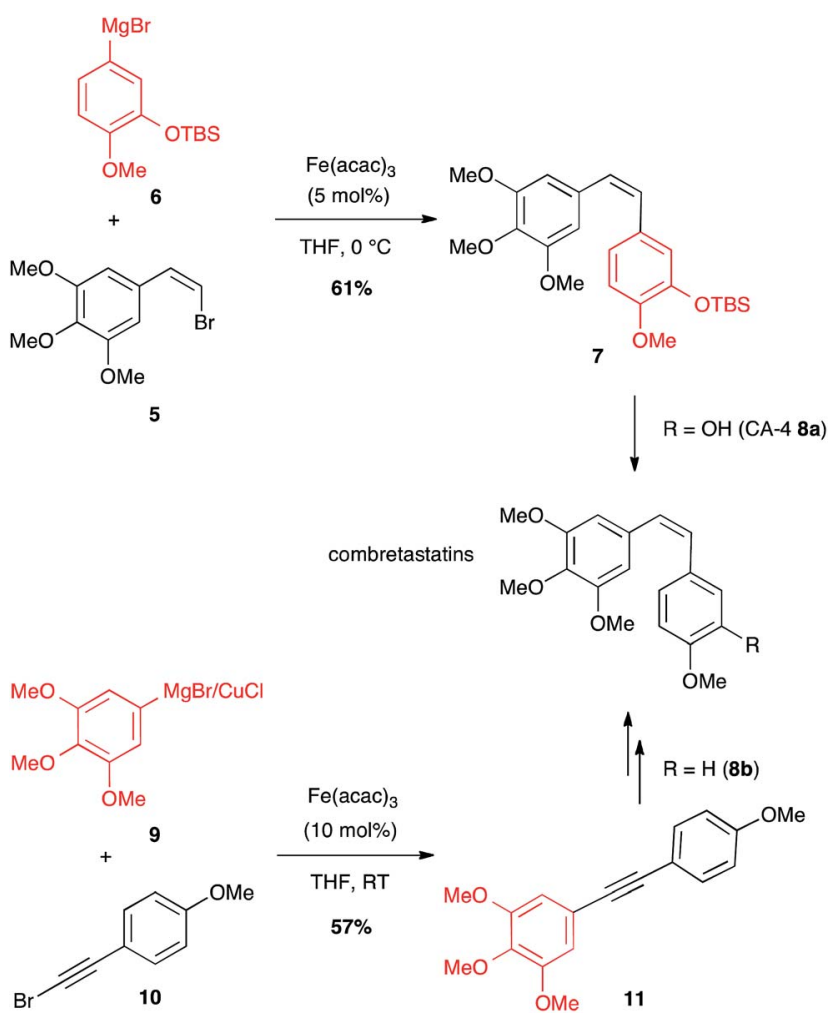

Scheme 4 Fe-catalysed cross-coupling for the synthesis of combretastatins. 
A4 (CA-4) protected as TBDMS ether 7 (61\% yield), which after deprotection led to the desired anticancer compound 8a (Scheme 4). ${ }^{23}$ Later on, another Fe-catalysed path to access combretastatins has been described. This latter does not involve any olefin as coupling partner with the arene reagent, but a bromoalkyne: bimetallic aryl magnesium/copper halide 9 reacted with bromoarylacetylene $\mathbf{1 0}$ under iron catalysis to afford the corresponding bi(aryl)acetylene 11 (57\% yield) that can be reduced to yield analogues of CA-4 $\mathbf{8 b}$ (Scheme 4$){ }^{24}$ It is worth noting that this is the single known example of Fe-catalysed coupling between a Grignard reagent and a bromalkyne.

Interestingly, less reactive $(E)$-chloroolefins are also good substrates for iron-catalysed coupling with aryl Grignard reagents: cinacalcet, a drug used for the treatment of secondary hyperparathyroidism, was prepared on a kilogram scale using this reaction between 12 and $\mathbf{1 3}$ as a key step (Scheme 5). ${ }^{25}$

Another amine-containing molecule, naftifine, an antifungal drug, was prepared by an iron-catalysed coupling of a $(E)$-chloroolefin 15 and phenyl Grignard reagent in high yield (89\%) and excellent stereoselectivity (Scheme 6). ${ }^{26}$
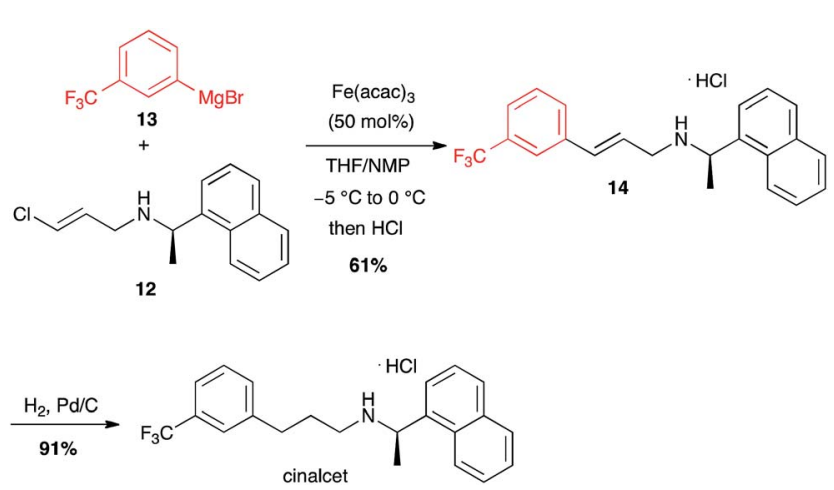

Scheme 5 Fe-catalysed coupling of aryl magnesium bromide with a $(E)$-chloroolefin for the synthesis of cinacalcet.

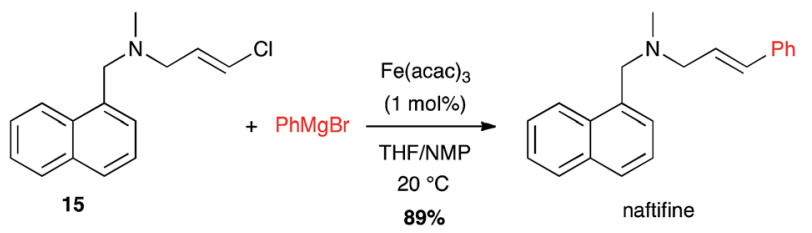

Scheme 6 Fe-catalysed coupling of phenyl magnesium bromide with a $(E)$-chloroolefin for the synthesis of naftifine.

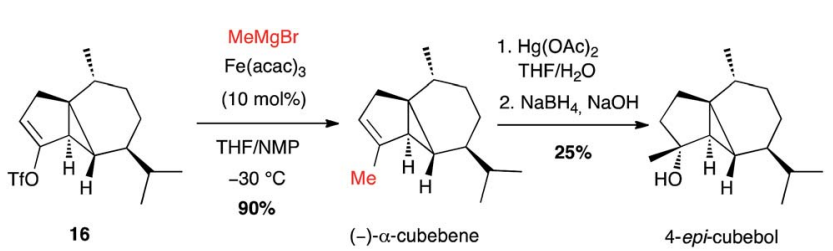

Scheme 7 Fe-catalysed coupling of methyl Grignard reagent with a vinyl triflate for the synthesis of $(-)$ - $\alpha$-cubebene and 4 -epi-cubebol.
Vinyl (pseudo)halides. However greatest applications with vinyl electrophiles in total synthesis have been found with vinyl triflates, as established by Fürstner. ${ }^{27}$ One of the major interest of these electrophiles is that enol triflates are readily accessible from the corresponding ketones (albeit with possible regioisomeric issues). Moreover, these triflates can in some cases be generated and used in cross-couplings without intermediate isolation.

This method has been mainly used to introduce a methyl group. Thus, the natural sesquiterpene $(-)-\alpha$-cubebene has been prepared in 2006 by Fürstner involving, at a late stage, coupling of methylmagnesium bromide with the isolated alkenyl triflate 16 in the presence of $\mathrm{Fe}(\mathrm{acac})_{3}(10 \mathrm{~mol} \%)$ in a THF/NMP mixture, in high yield (90\%). 4-epi-Cubebol has then been further obtained (Scheme 7). ${ }^{28}$

The same year, Isobe used this methodology to perform the synthesis of the right-hand segment of ciguatoxin. ${ }^{29}$ A methyl group was then successfully introduced from an isolated triflate generated from $\mathrm{PhNTf}_{2}$, using a stoichiometric amount of $\mathrm{Fe}(\mathrm{acac})_{3}(89 \%$ from ketone 17; Scheme 8).

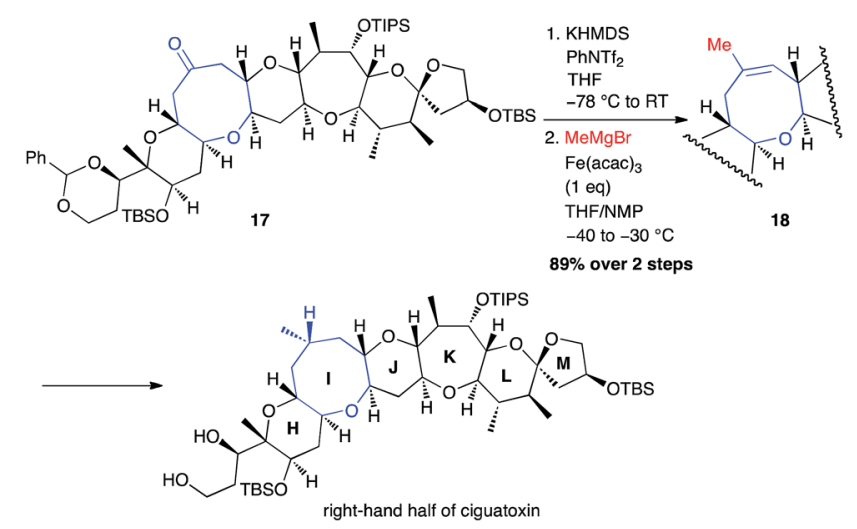

Scheme 8 Fe-catalysed coupling of methyl Grignard reagent with a vinyl triflate for the synthesis of the right-hand segment of ciguatoxin.
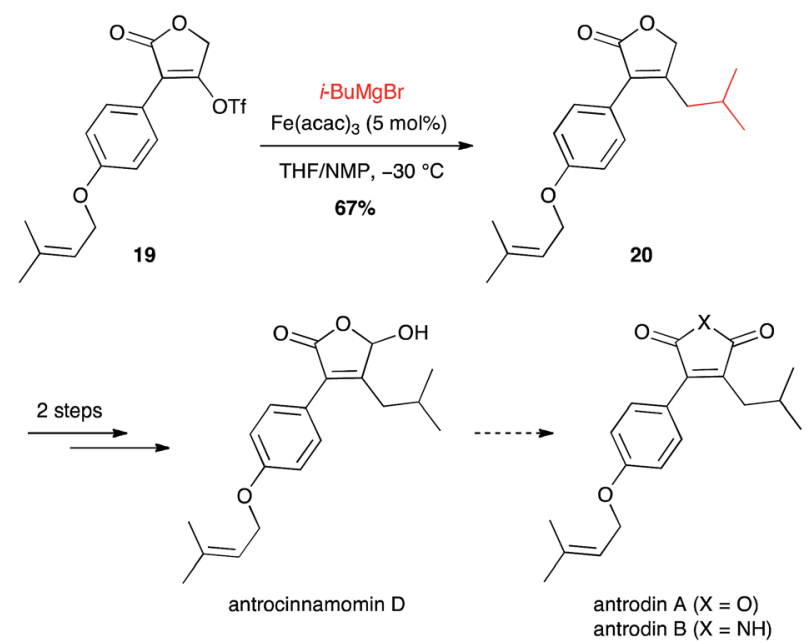

Scheme 9 Fe-catalysed coupling of methyl Grignard reagent with a vinyl triflate for the synthesis of antrocinnamomin $\mathrm{D}$ and antrodins. 
i-Butyl moiety has also been introduced for the synthesis of maleic anhydrides and derivatives, constituents of Antrodia camphorata: antrocinnamomin D and antrodins (Scheme 9). ${ }^{30}$ Interestingly the coupling between $\mathrm{i}-\mathrm{BuMgBr}$ and the vinyl triflate 19 with the inexpensive $\mathrm{Fe}(\mathrm{acac})_{3}$ ( $\left.5 \mathrm{~mol} \%\right)$ was more efficient than the Suzuki-Miyaura coupling from i-BuB $(\mathrm{OH})_{2}$ and $10 \mathrm{~mol} \% \mathrm{Pd}(\mathrm{dppf}) \mathrm{Cl}_{2}$ (67\% vs. 55\% yield for compound 20 ).

$\mathrm{Yu}$ and Nicolaou independently investigated the Fe-catalysed cross-coupling with MeMgBr directly on a crude triflate. Thus, Yu's synthesis of $(+)$-asteriscanolide involved the coupling of triflate 22 at an intermediate stage, generated with a $88: 12$ regioisomeric ratio, affording the methylated adduct 23 in 58\% yield from the ketone 21 (Scheme 10). ${ }^{31}$

In his synthesis of cylindrocyclophane by Nicolaou, two methyl groups were introduced simultaneously and the generation of the bis-triflate did not undergo any isomeric issues since it took place at a benzylic position, and the coupling occurred smoothly to afford the double methylated product 25 in $80 \%$ yield over two steps from 24 (Scheme 11). ${ }^{32}$
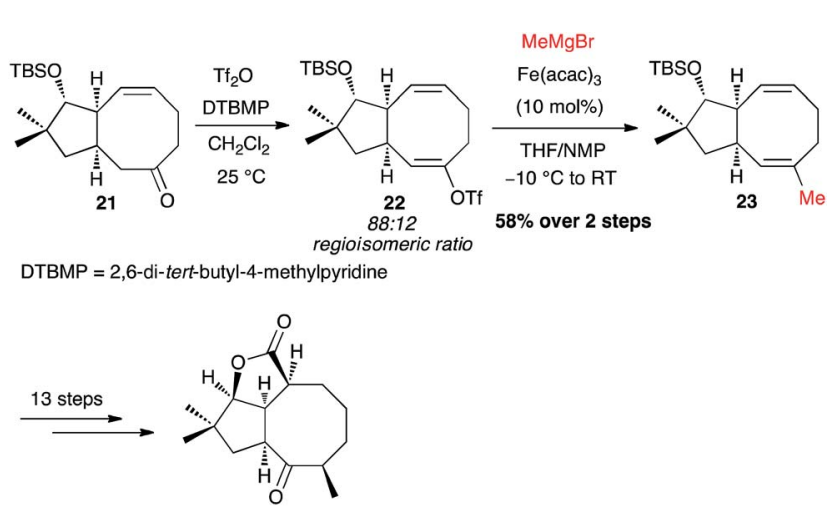

(+)-asteriscanolide

Scheme 10 Fe-catalysed coupling of methyl Grignard with a vinyl triflate for the synthesis of $(+)$-asteriscanolide.
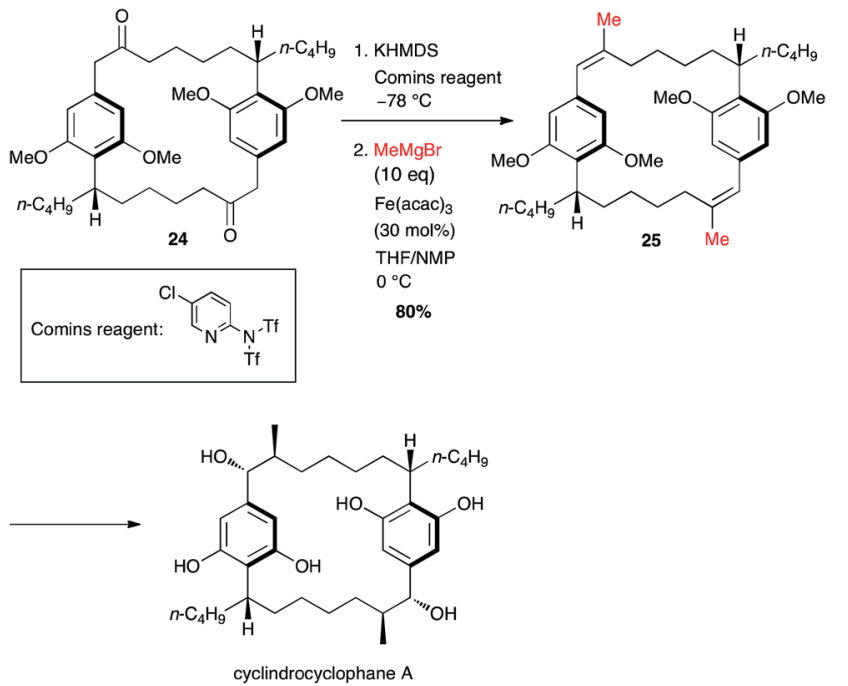

Scheme 11 Fe-catalysed coupling of methyl Grignard with a bisvinyltriflate for the synthesis of cylindrocyclophane A.
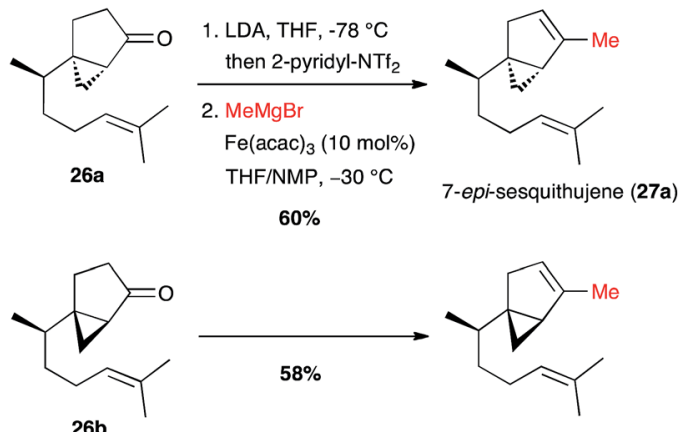

sesquithujene (27b)

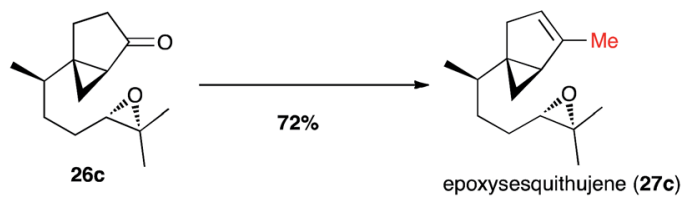

Scheme 12 Fe-catalysed coupling of methyl Grignard with a vinyl triflate for the synthesis of three members of the sesquithujene family.

Finally, Fürstner reported the full one-pot triflate formation/ cross-coupling at the last step of the synthesis of sesquithujene natural products (Scheme 12). ${ }^{33}$ Vinyl triflates were generated from 26a-c under kinetic conditions with 2-pyridinyl-NTf 2 , a Comins' reagent analogue, leaving unaffected the chiral cyclopropyl moieties. Then the reagents for the cross-coupling were added (MeMgBr, [Fe] cat. and NMP co-solvent), and the coupling products $27 \mathbf{a}-\mathbf{c}$ were obtained in $60-72 \%$ yield. Interestingly, under these conditions the coupling with the Grignard reagent reacted selectively with the vinyl triflate and the epoxide moiety remained unchanged in the synthesis of epoxysesquithujene 27c.

Besides classical leaving groups met in cross-couplings (I, Br, OTf,...), phosphates can also be used on the electrophilic partner. Thus, dienol phosphate $\mathbf{2 8}$ reacted very well with alkyl Grignard reagent 29 at low iron catalyst loading ( $1 \mathrm{~mol} \%$ ) while maintaining the double bond geometry. ${ }^{34,35}$ This strategy has been successfully used to access the Red Bollworm Moth (Diparopsis castanea) pheromone 30 (75\% over two steps, Scheme 13). ${ }^{35}$

Selective formation of (Z)-enol phosphate $\mathbf{3 1}$ from a ketoester, followed by an iron-catalysed coupling with methylmagnesium chloride, allowed Evans to prepare a key trisubstituted olefin 32, en route to the total synthesis of salvinorin A, a potent $\kappa$ opioid receptor agonist (Scheme 14). ${ }^{36}$

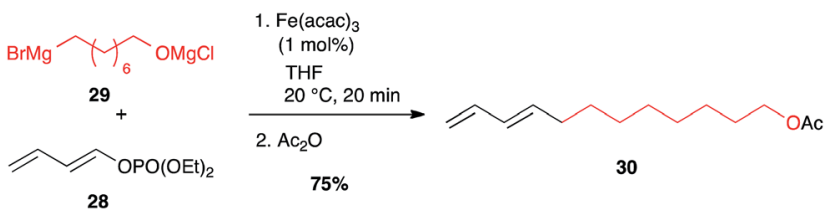

Scheme 13 Fe-catalysed coupling of an alkyl Grignard with a (E)-dienol phosphate for the synthesis of the Diparopsis castanea pheromone. 
<smiles>C=CC[C@H](COC)/C(=C/COCC)OCC</smiles>

31

$65 \%$

32

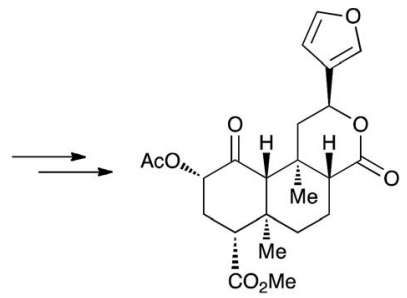

Salvinorin A

Scheme 14 Fe-catalysed coupling of methyl Grignard with a (Z)-enol phosphate for the synthesis of salvinorin A.

gem-Dihalogenoalkenes. gem-Dihalogenoalkenes constitute an interesting and specific class of electrophiles with a particular behavior towards organo-magnesium and -lithium reagents in Fe-catalysed cross-couplings, which met application in the synthesis of natural products. Thus, bioactive compounds derived from the chimanines, natural 2-substituted quinolines isolated from a Rutaceae, were prepared from quinolyl-gemdihalogenoalkenes and organomagnesium reagents in presence of $\mathrm{Fe}(\mathrm{acac})_{3}$. While dibromo-compound 33 undergoes reduction to selectively afford the $(E)$-bromoalkene $\mathbf{3 4}$ (able to react by cross-coupling with a further equivalent of RMgX to afford 35), ${ }^{37}$ in contrast, 1,1-dichloroalkenes react rapidly to afford the disubstituted product, even if less than 2 equiv. of $\mathrm{RMgX}$ are used..$^{38}$ Thus, gem-dichlorovinyl quinoline $\mathbf{3 6}$ has been engaged in cross-coupling with bis-Grignard reagent $\mathbf{3 7}$ to perform an intermolecular followed by an intramolecular cross-coupling leading thus to an original cyclohexylidene moiety on this family of bioactive compounds ( $84 \%$ for $\mathbf{3 8}$, Scheme 15$).^{38}$

Very recently, Fürstner developed a brilliant methodology to access methyl-terminated alkynes from MeLi and gem-dichloro-
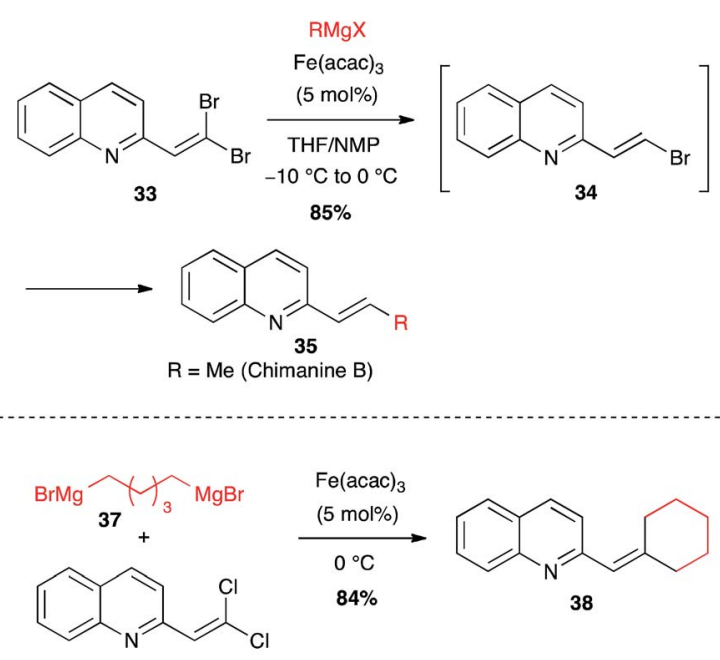

36

Scheme 15 Fe-catalysed coupling of an alkyl Grignard with gemdihaloalkenes for the synthesis of chimanine derivatives. olefins obtained from lactones. These non-terminal alkyne moieties are then involved in ring closing alkyne metathesis (RCAM) and tulearin A and brefeldin A have been prepared through this pathway (Schemes 16 and 17)..$^{39,40}$ The reaction between MeLi and gem-dichloroolefin 39, affording the methylcapped acetylenic compound $\mathbf{4 2}$, is not stricto sensu a crosscoupling: a first $\mathrm{Cl}-\mathrm{Li}$ exchange occurs and the $\mathrm{MeCl}$ formed is trapped by compound $\mathbf{4 0}$ and the rearrangement takes place to yield the target product $\mathbf{4 2}$ in $83 \%$ yield (Scheme 16). Even if this reaction is possible without catalyst, the presence of $\mathrm{Fe}(\mathrm{acac})_{3}$ and 1,2-diaminobenzene ( 5 and $25 \mathrm{~mol} \%$, respectively) significantly enhanced the course of the reaction $(2 \mathrm{~h} v s .48 \mathrm{~h}$ reaction time without $[\mathrm{Fe}])$. Thus, starting from 39, tulearin A was obtained in 6 steps. $^{39}$

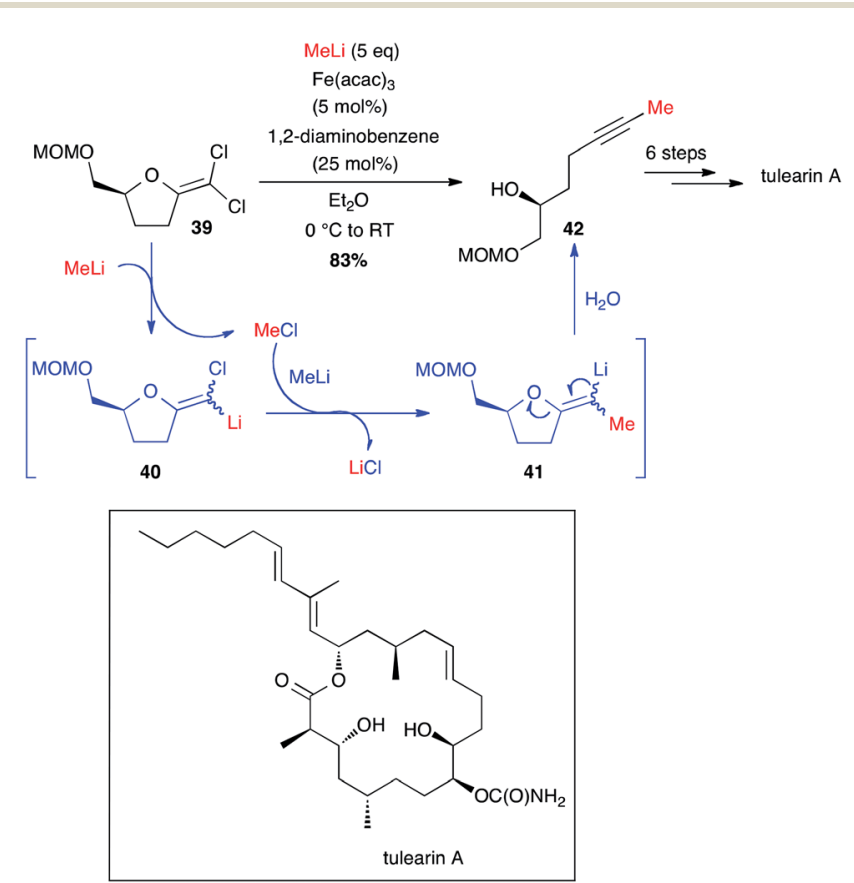

Scheme 16 Fe-catalysed coupling of methyl lithium with a gemdichloroalkene for the synthesis of tulearin $\mathrm{A}$.
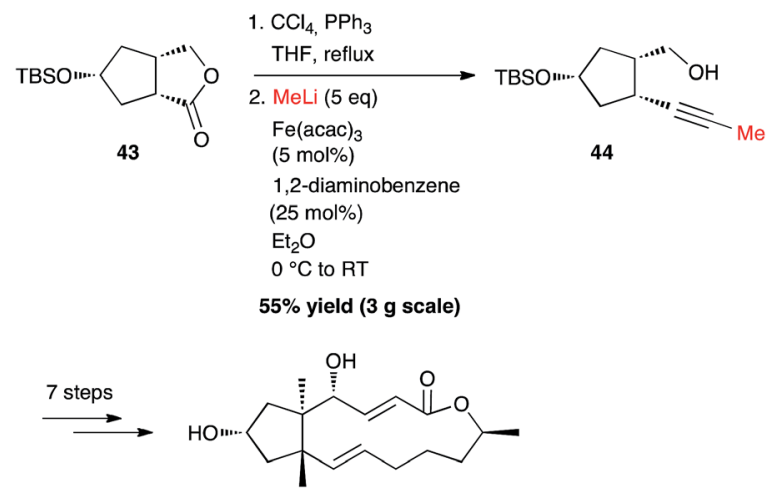

Scheme 17 Fe-catalysed coupling of methyl lithium with gemdichloroalkene for the synthesis brefeldin A. 
Interestingly, starting from $3 \mathrm{~g}$ of lactone $\mathbf{4 3}$, it was possible to synthesize the methyl-capped alkyne 44 in $55 \%$ yield, as an intermediate for the preparation of brefeldin A, a most studied biologically active macrolide from Penicillium decumbens (Scheme 17). ${ }^{40}$

Imidoyl chloride. Olsson demonstrated the possibility to introduce various moieties on an imidoyl chloride with organomagnesium reagents to access benzodiazepine analogues (clozapines). Interestingly, the Grignard reagent 45 selectively reacted with the imidoyl chlorides 46 without affecting the chlorine atom connected to the arene (Scheme 18). ${ }^{41}$

\subsection{With aryl (pseudo)halides}

In contrast with palladium-catalysed cross-couplings, arylchlorides, -tosylates and -triflates have been shown to be the best partners for iron-catalysed reactions with Grignard reagents, bromo-/iodoarenes being poorer reagents. ${ }^{\mathbf{4 2}}$ Fürstner has developed many iron-catalysed coupling reactions between organomagnesium reagents and various Ar-X electrophilic partners, and showed that alkyl Grignard reagents react very well with aromatic and heteroaromatic triflates in high yields. FTY720, an immunosuppressive agent was thus prepared in a multigram scale by Fürstner through Fe-catalysed coupling of an alkyl Grignard reagent 47 and an aryl triflate 48 (64\%, Scheme 19). ${ }^{43}$

In 2003, these coupling reactions have been applied to an elegant one-pot synthesis of an odoriferous alkaloid from animal origin, $(R)$-muscopyridine. Indeed, mixing 2-chloro-6triflate-pyridine $\mathbf{5 0}$ with an enantiomerically pure alkyl
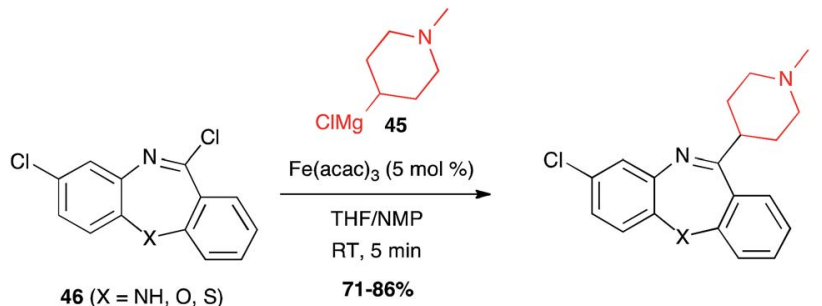

$46(X=\mathrm{NH}, \mathrm{O}, \mathrm{S})$

Scheme 18 Fe-catalysed coupling of a Grignard reagent with imidoyl chlorides to synthesize clozapines.

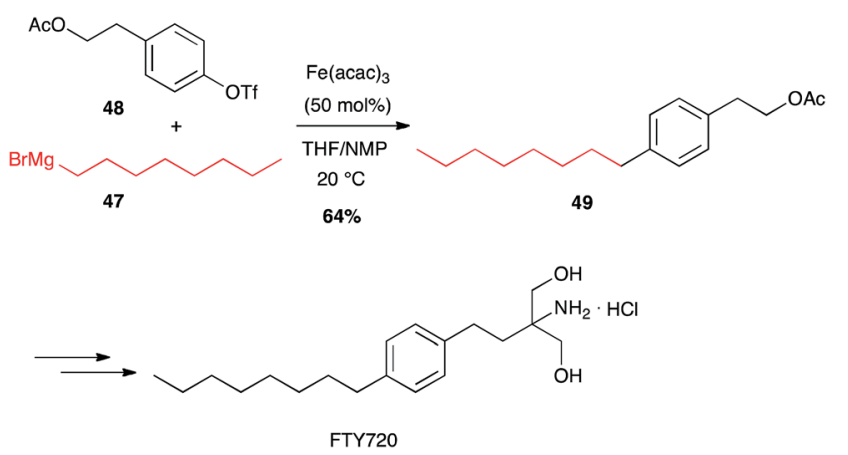

Scheme 19 Fe-catalysed coupling of octyl magnesium bromide with an aryl triflate for the synthesis of FTY720.
Grignard reagent $\mathbf{5 1}$ in the presence of an iron-salen salt ( $5 \mathrm{~mol} \%$ ) in a THF/NMP mixture resulted in a selective reaction with the-OTf group. Then, addition of 6-heptenylmagnesium bromide 52 (reacting on the $\mathrm{C}-\mathrm{Cl}$ site), afforded the expected double adduct 53 (64\%). This latter then underwent a ringclosing metathesis, and a hydrogenation to afford the expected natural product in $57 \%$ yield (Scheme 20$).{ }^{\mathbf{4 4}}$

This group confirmed that halopyridines are indeed excellent substrates for iron-catalyzed Grignard couplings. Thus isooncinotine was prepared using as a key step the coupling of 2,6-dichloropyridine $\mathbf{5 4}$ with a functionalized alkyl Grignard reagent 55 in the presence of $\mathrm{Fe}(\mathrm{acac})_{3}$ in the THF/NMP solvent mixture at $0{ }^{\circ} \mathrm{C}(83 \%$ yield of 56 ; Scheme 21$) .{ }^{45}$

In 2014, Schulz exemplified the coupling of 2-chloropyridine 57 with alkyl Grignard reagents under iron catalysis for the preparation of volatile pyridine alkaloids 58 produced by Streptomyces sp. (Scheme 22). ${ }^{\mathbf{4 6}}$

Moreover, Risatti performed a high yielding $\mathrm{Fe}(\mathrm{acac})_{3}$-catalysed coupling between a functionalized chloropyridine $\mathbf{5 9}$ and cyclopropylmagnesium bromide in their route to the synthesis of a dual NK-1/serotonin receptor antagonist (Scheme 23). ${ }^{47}$

It is worth noting that Sörensen has used a coupling with alkyl Grignard reagent $\mathbf{6 1}$ with the 2-chloropyridine 62 under
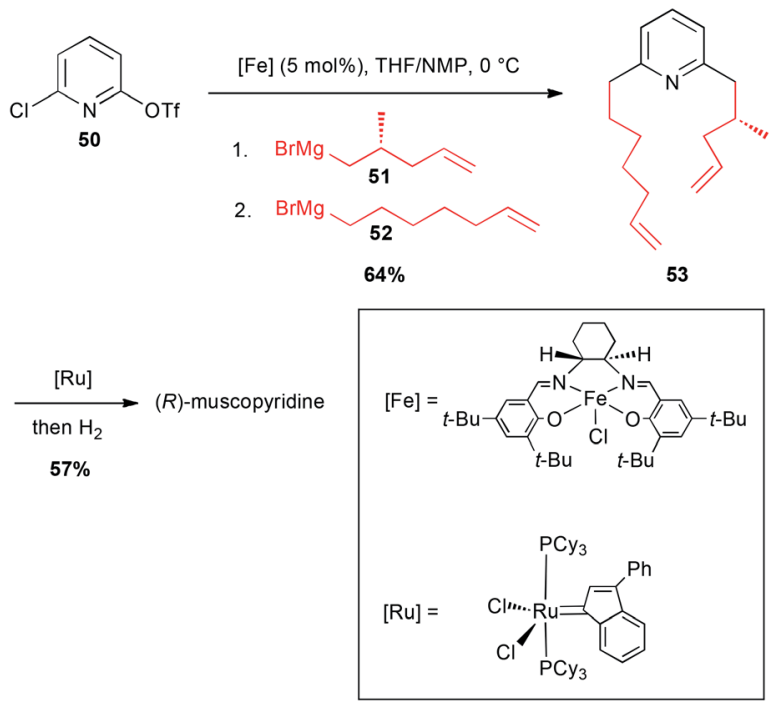

Scheme 20 Fe-catalysed coupling of alkyl Grignard reagents with a chloropyridinyl triflate for the synthesis of $(R)$-muscopyridine.

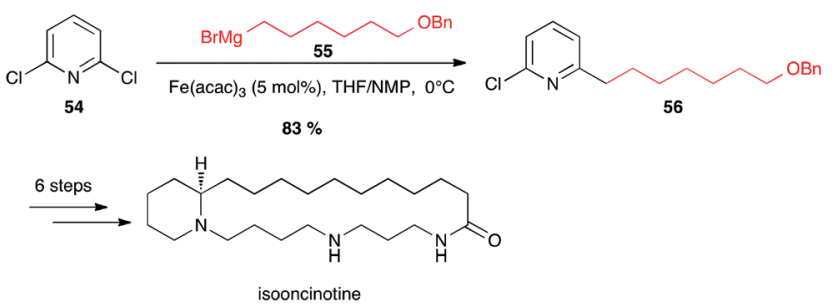

Scheme 21 Fe-catalysed coupling of alkyl Grignard with a dichloropyridine for the synthesis of isooncinotine. 


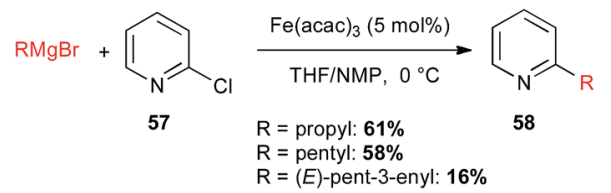

Scheme 22 Fe-catalysed coupling of alkyl Grignard reagents with 2 -chloropyridine for the synthesis of streptopyridines.
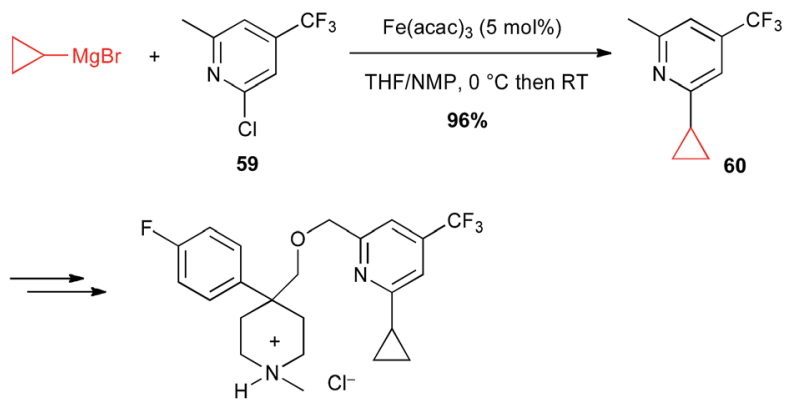

NK1/serotonin receptor antagonist

Scheme 23 Fe-catalysed coupling of cyclopropylmagnesium bromide with a chloropyridine derivative for the synthesis of a NK1/serotonin receptor antagonist.

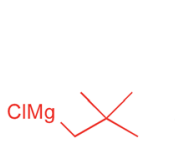

61<smiles>COC(=O)c1ccnc(Cl)c1</smiles>

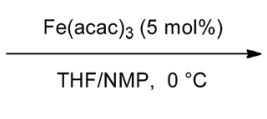

$73 \%$

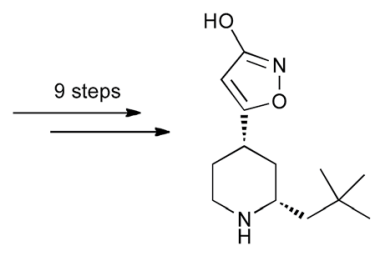

AZD6564
Scheme 24 Fe-catalysed coupling of alkyl Grignard with a 2-chloropyridine derivative for the synthesis of fibrinolysis inhibitor AZD6564.

iron catalysis for a large scale preparation $(2 \mathrm{~kg})$ of the 3-isoxazolol fibrinolysis inhibitor AZD6564 (Scheme 24). ${ }^{48}$

Iron-catalysed alkyl Grignard couplings can be applied to other heteroaryl halides. In particular, Cabri showed that a 2-chloropurine 64 can be coupled with $n$-butyl Grignard reagent in the presence of $\mathrm{Fe}(\mathrm{acac})_{3}$ in the THF/NMP solvent mixture at $0{ }^{\circ} \mathrm{C}$, to afford a key intermediate 65 in 91\% yield in the total synthesis of the adenosine $\mathrm{A}_{2 \mathrm{~A}}$ receptor antagonist ST1535 (Scheme 25). ${ }^{49}$

\subsection{With alkyl (pseudo)halides}

Total synthesis of spirangien A has been in the focus of two different investigations with a Fe-catalysed step to introduce the terminal 2-butenyl fragment. Thus, Cossy has used an iron-

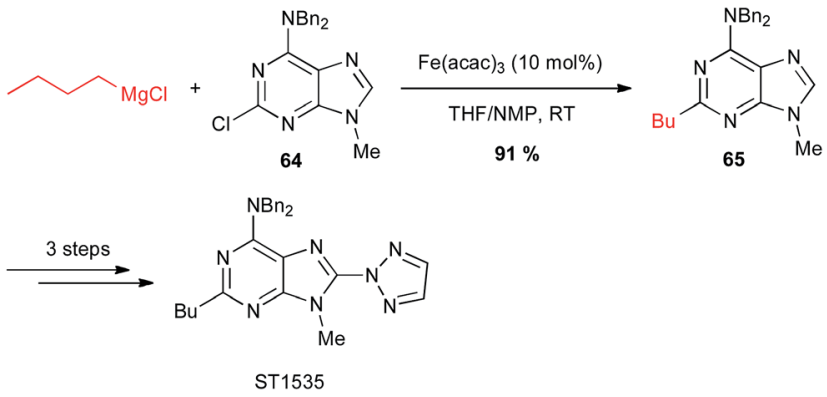

Scheme 25 Fe-catalysed coupling of alkyl Grignard with a 2-chloropurine derivative for the synthesis of adenosine $A_{2 A}$ receptor antagonist ST1535.

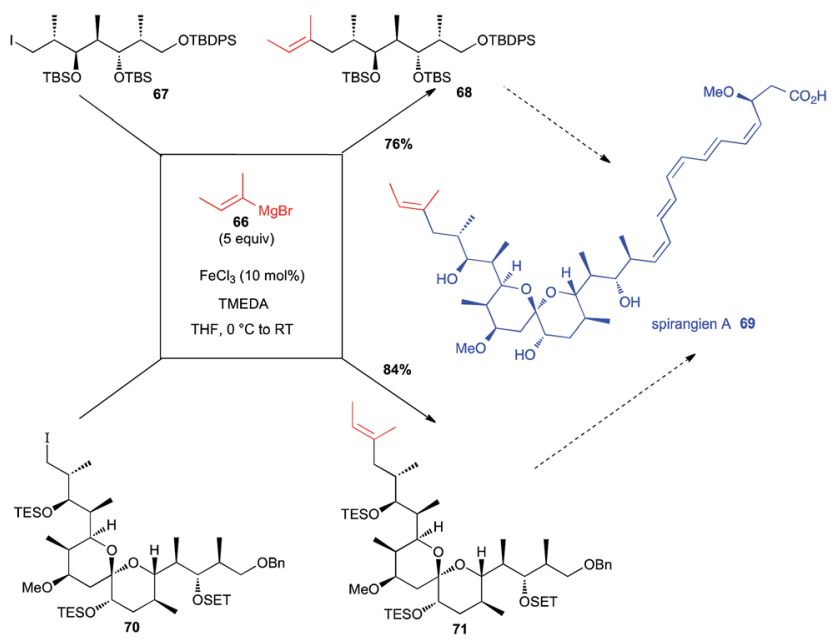

Scheme 26 Fe-catalysed coupling of a vinyl Grignard with a primary alkyl iodide for the synthesis of spirangien $A$.

catalysed coupling between an alkenyl Grignard reagent 66 and a primary alkyl iodide $\mathbf{6 7}$ in an early step of her synthesis of the spiroketal core of spirangien A (76\% yield for 68 , Scheme 26). ${ }^{50}$ It is worth noting that this reaction was much more efficient than the Negishi cross-coupling reaction. More recently, Rizzacasa used the same iron-catalysed coupling between 66 and a primary alkyl iodide $\mathbf{7 0}$, but in a later step of their formal synthesis of spirangien A, still in good yield (84\% yield for $\mathbf{7 1}$, Scheme 26). ${ }^{51}$

In 2015, Totah and Lam reported the synthesis of a model fragment $\mathbf{7 4}$ of spirastrellolide A through an iron catalysed cross-coupling from rac-72 (Scheme 27). ${ }^{52}$ The vinyl Grignard reagent was generated in situ by I-Li exchange from enantiopure 1-iodo-1,4-diene 73, followed by transmetallation with $\mathrm{MgBr}_{2}$ without any issues, and the Fe-catalysed coupling with rac-72 occurred to afford the target molecule $\mathbf{7 4}$ as a mixture of two diastereomers.

Secondary aliphatic bromides are also good substrates for iron-catalysed couplings with Grignard reagents. In this line, Cossy reported a coupling of a vinyl Grignard with a $C$-bromopyranoside 75 under Fe-catalysed conditions to prepare a key tetrahydropyrane $\mathbf{7 6}$ en route to the total synthesis of 


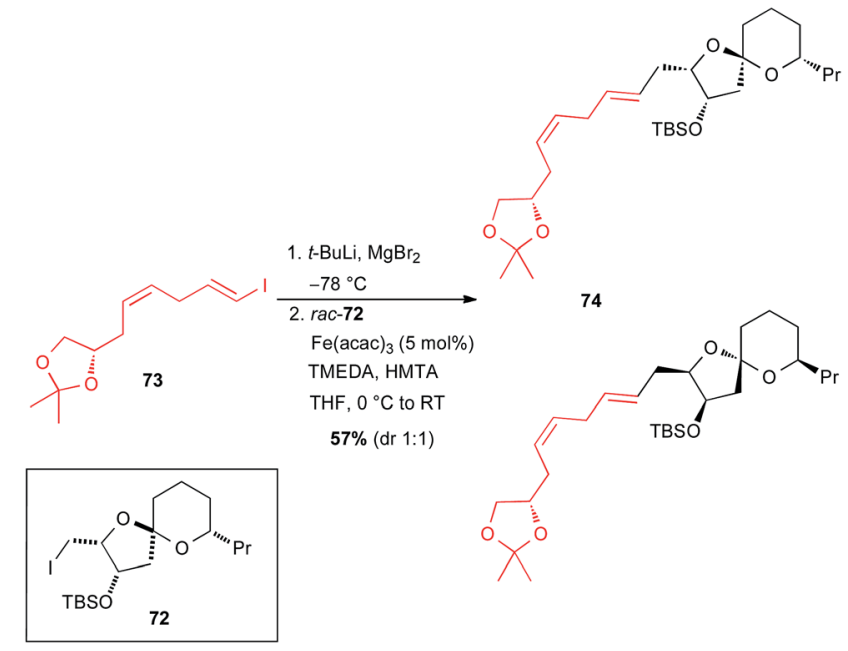

Scheme 27 Fe-catalysed coupling of a vinyl Grignard with a primary alkyl iodide for the synthesis of a model fragment of spirastrellolide $A$.<smiles>CC(=O)OC[C@H]1OC(Br)[C@H](OC(C)=O)[C@H](OC(C)=O)[C@@H]1OC(C)=O</smiles>

75

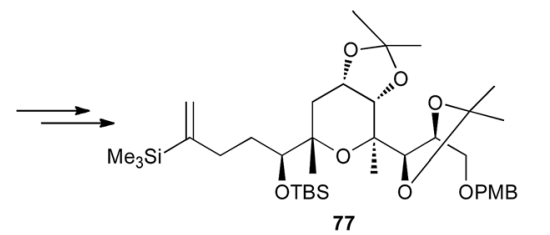

Scheme 28 Fe-catalysed coupling of a vinyl Grignard with a secondary alkyl bromide for the synthesis of a tetrahydropyrane core of amphidinol 3.

amphidinol 3. This cross-coupling exhibits excellent chemoand diastereoselectivity since it tolerates the presence of acetoxy moieties and the product is obtained in $72 \%$ yield with $\mathrm{dr}=$ $9: 1$ (Scheme 28)..$^{53}$

Yamada also reported in their formal total synthesis of $(+)$-allokainic acid the use of an iron-catalysed coupling between a vinyl Grignard and a secondary bromoalkyl derivative $\mathbf{7 8}$, although the yield of 79 remained low (36\%) due to competitive opening of the pyrrolidine ring (Scheme 29). ${ }^{54}$

Iodocholestene was successfully reacted with an alkynyl Grignard reagent 80 under iron(II)-catalysis to afford the natural

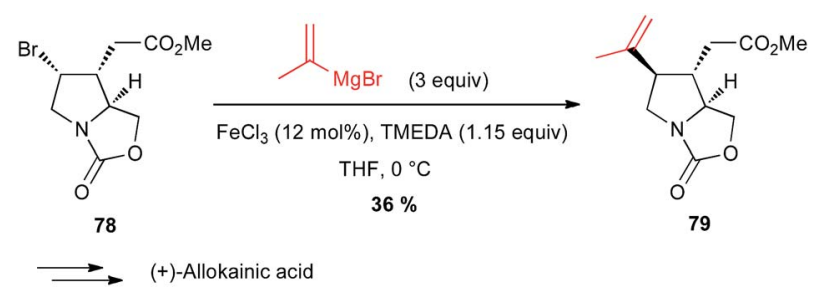

Scheme 29 Fe-catalysed coupling of a vinyl Grignard with a secondary alkyl bromide for the synthesis of (+)-allokainic acid.

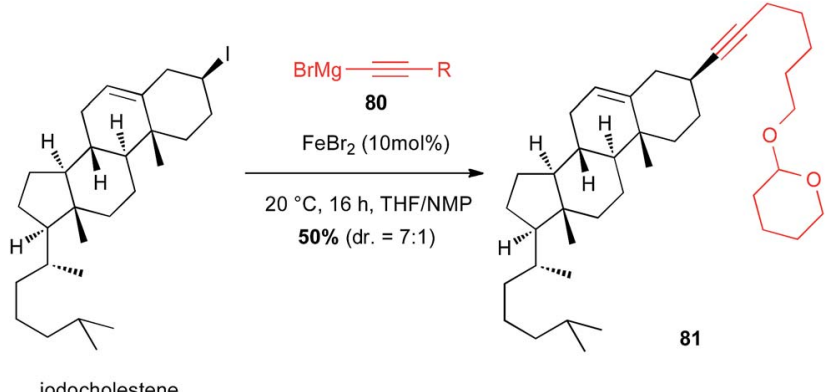

Scheme 30 Fe-catalysed coupling of an alkynyl Grignard with a secondary alkyl iodide for the synthesis of cholestene derivative.

product derived compound $\mathbf{8 1}$ in moderate yield (50\%) and selectivity favouring retention of configuration ( $\mathrm{dr}=7: 1$ ) (Scheme 30)..$^{55}$

In 2015 , an important breakthrough was reported by Nakamura who performed a Fe-catalysed enantioselective crosscoupling of racemic $\alpha$-chloroesters with aryl Grignard reagents in presence of a $C_{2}$-symmetric bisphosphine ligand..$^{56}$ Moreover, this methodology allowed the preparation of the chiral nonracemic NSAID naproxen and dexibuprofen (Scheme 31). The coupling between chloropropionate $\mathbf{8 2}$ and the corresponding aryl magnesium bromides afforded the esters 83a and $\mathbf{8 3 b}$ with the same $74 \%$ ee for naproxen and dexibuprofen esters, respectively. However, saponification and crystallization with octyl amine allowed significant enantioenrichment to $86 \%$ and $98 \%$ ee, respectively. On a mechanistic standpoint, a catalytic

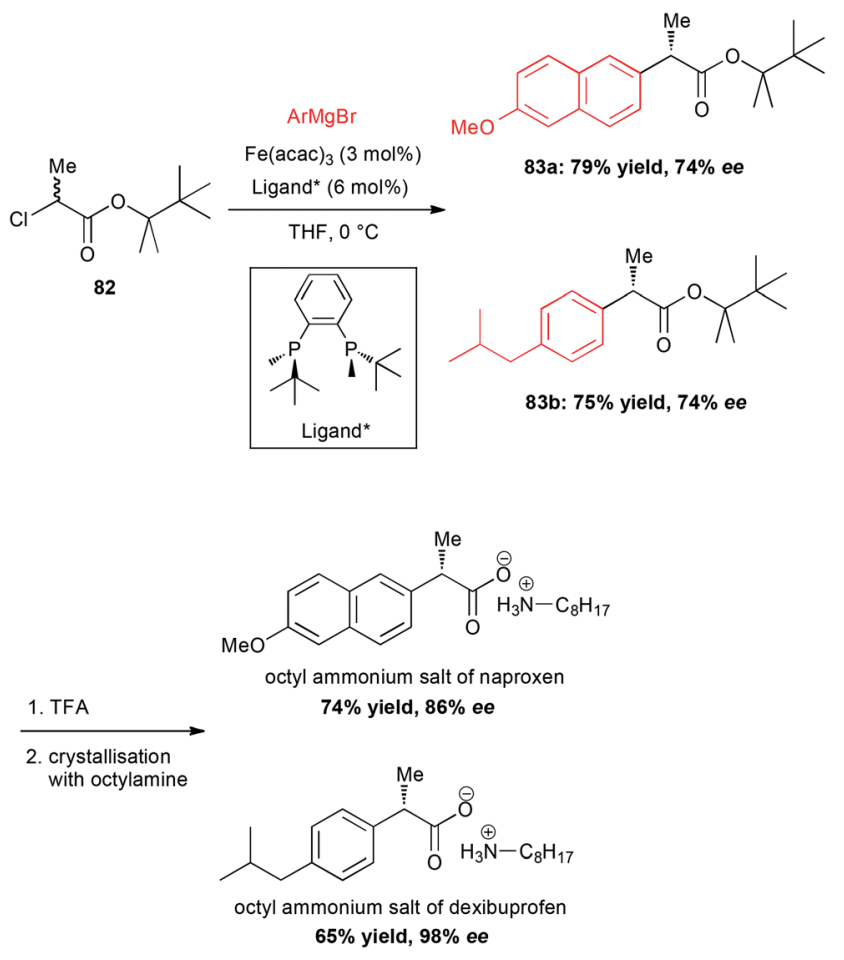

Scheme 31 Fe-catalysed enantioselective cross-coupling of racemic $\alpha$-chloroesters with aryl Grignard reagents to prepare naproxen and dexibuprofen. 
cycle involving a radical intermediate formed by halogen abstraction and Fe(I) species with a chiral ligand has been proposed.

\subsection{With acyl chlorides}

Iron-catalysed processes are also powerful tools to access ketones: Grignard reagents in presence of $\mathrm{Fe}(\mathrm{acac})_{3}$ catalyst were able to perform the formal nucleophilic substitution onto acyl chlorides and thioesters, without further addition to generate the tertiary alcohol, as demonstrated by Marchese. ${ }^{57}$ In 2003, Fürstner extended this methodology to functionalized sophisticate molecules such as an enantiopure thiazolidinone 84 bearing an acyl chloride moiety, in his synthesis of latrunculin B. The reaction proceeds cleanly, affecting only the acyl group and affording thus the ketone 85 in good $80 \%$ yield. Moreover, a second Fe-catalysed step was also involved in this total synthesis between a homopropagylic Grignard reagent 86 and a vinyl triflate $\mathbf{8 7}$ (Scheme 32$){ }^{58}$

More recently, the same group applied this reaction between a Grignard reagent $\mathbf{8 9}$ terminated with an acetylenic moiety and an acyl chloride 90 to prepare a precursor 91 of $(R, Z)$-muscenone (Scheme 33). ${ }^{59}$

\subsection{Ring opening}

Propargyl epoxides. The addition of Grignard reagents onto enantiopure propargyl epoxides has also been shown by

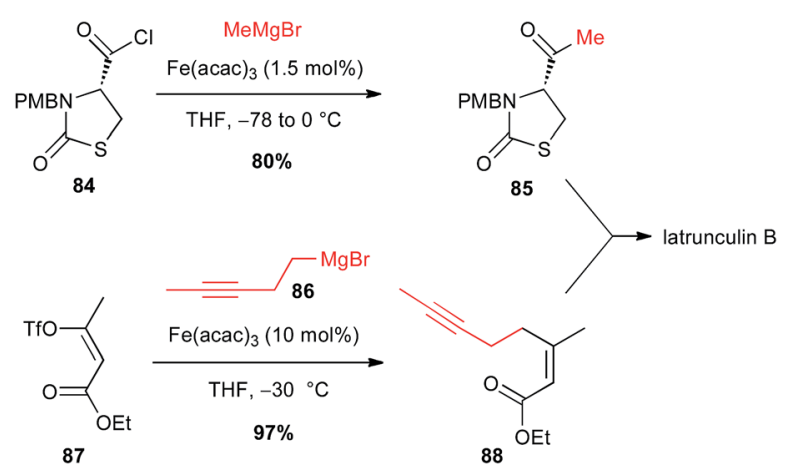

Scheme 32 Fe-catalysed acylation of an alkyl Grignard with an acyl chloride for the synthesis of latrunculin B.

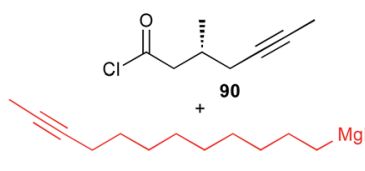

89

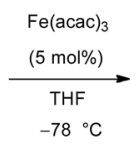

$79 \%$

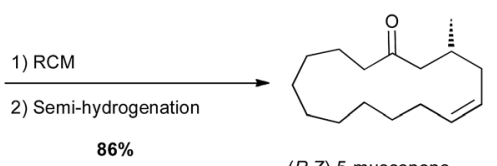

$(R, Z)-5$-muscenone

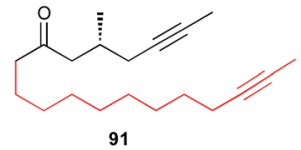

91
Scheme 33 Fe-catalysed acylation of an alkyl Grignard with an acyl chloride for the synthesis of $(R, Z)$-muscenone.
Fürstner to be a very elegant manner to obtain optically active allenols though $\mathrm{S}_{\mathrm{N}} 2^{\prime}$ process. Thus, this $\mathrm{Fe}(\mathrm{acac})_{3}$-catalysed reaction proceeded with good $\mathrm{C} 1$ to axial chirality transfer $(62 \%$ yield, dr $>8: 1$ ) for the preparation of a syn allenol 93, which was a key intermediate in the total synthesis of amphidinolides $\mathrm{X}$ and $\mathrm{Y}$, with regards to the oxygenated ring systems (Scheme 34 and Fig. 1). ${ }^{60,61}$

On the contrary, Lee found that iron-catalyzed $\mathrm{S}_{\mathrm{N}} 2^{\prime}$ opening of an intermediate epoxyalkyne $\mathbf{9 4}$ in their synthesis of

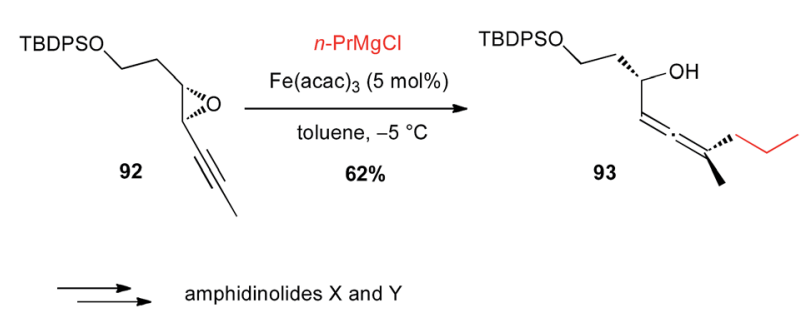

Scheme 34 Fe-catalysed coupling of propyl magnesium chloride with a propargyl epoxide for the synthesis of amphidinolides $X$ and $Y$.

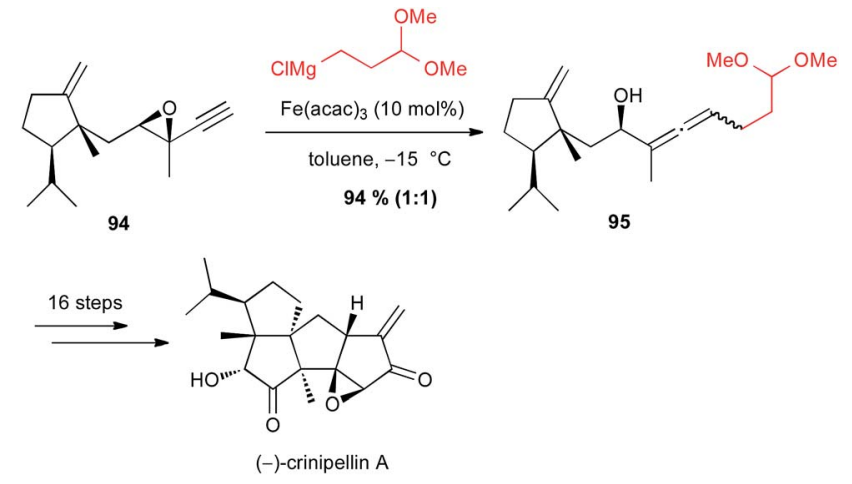

Scheme 35 Fe-catalysed coupling of a Grignard reagent with a propargyl epoxide for the synthesis of (-)-crinipellin A.

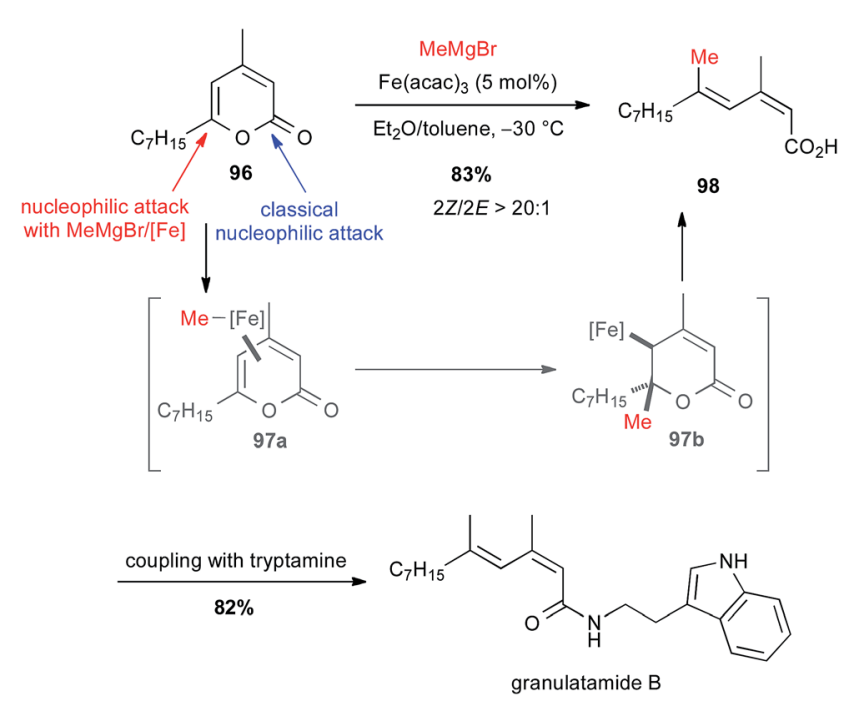

Scheme 36 Fe-catalysed ring-opening/cross-coupling with methyl Grignard and 2-pyrones for the synthesis of granulatamide B. 
(-)-crinipellin A was not diastereoselective, since 95 was obtained in $94 \%$ yield as a $1: 1$ mixture of two diastereomers (Scheme 35). ${ }^{62}$

2-Pyrones. The ring opening of 2-pyrones with nucleophiles classically occurs on the carbonyl group. In contrast, the reaction between 2-pyrones and Grignard reagents with $\mathrm{Fe}(\mathrm{acac})_{3}$ in toluene or ether solvent (or a mixture of both) leads to the formation of 2,4-dienoic acids with selective $2 Z$ configuration. ${ }^{63}$ Thus, pyrone 96 reacted under these conditions to give dienoic acid $98(2 Z / 2 E>20: 1)$ in $83 \%$ yield. This latter, after peptidic coupling with tryptamine, leads to granulatamide $\mathrm{B}$, a cytotoxic compound found in Eunicella granulate (Scheme 36).

The mechanism of this cross-coupling is supposed to go through a $\pi$-complex 97a followed by conjugate addition of

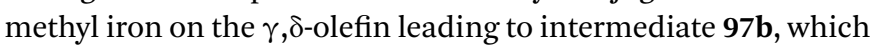
affords by $\beta$-elimination the target compound $\mathbf{9 8}$ with desired geometry.

\section{Lewis acid catalysis}

Iron salts are much known as one of the first Lewis acids used in the Friedel-Crafts reaction. Bach used $\mathrm{FeCl}_{3}$ in an intermolecular Friedel-Crafts reaction between a phenol derivative $\mathbf{9 9}$ and

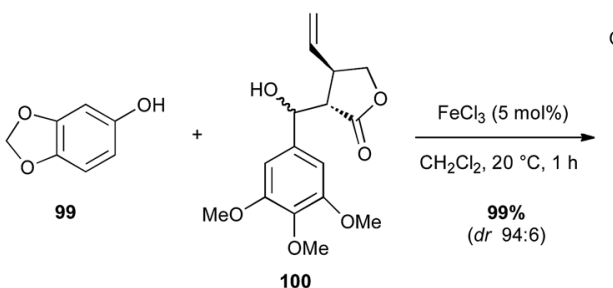

$\longrightarrow(-)$-podophyllotoxin

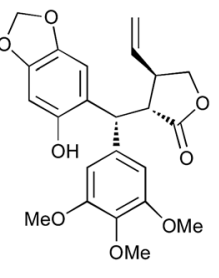

101
Scheme 37 Fe-catalysed Friedel-Crafts reaction with a benzyl alcohol for the synthesis of (-)-podophyllotoxin.

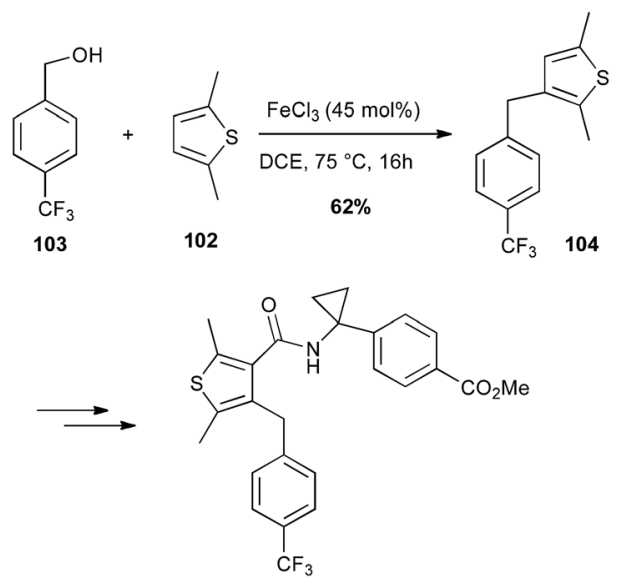

prostaglandin EP4 receptor antagonist

Scheme 38 Fe-catalysed coupling of 2,5-dimethylthiophene with benzyl alcohol for the synthesis of a prostaglandin EP4 receptor antagonist.

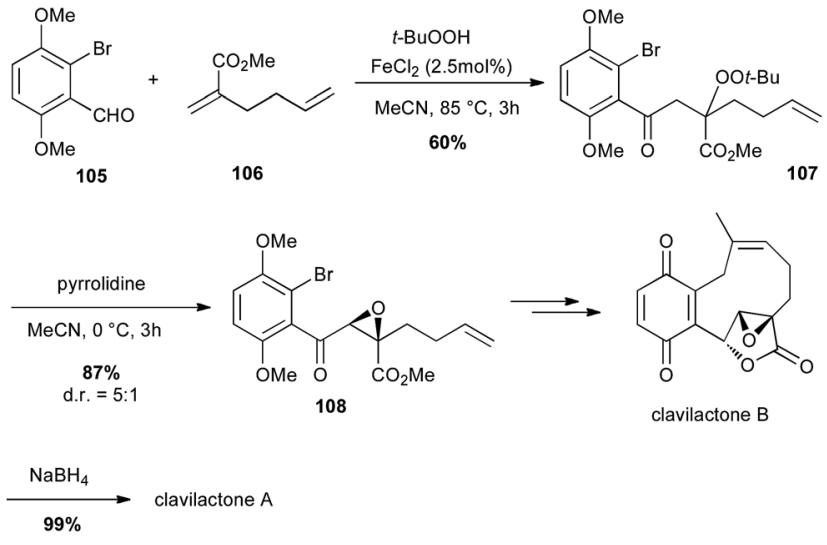

Scheme 39 Fe-catalysed carbonylation-peroxidation of an olefin for the synthesis of $(+/-)$-clavilactones $A$ and $B$.

a functionalized benzyl alcohol $\mathbf{1 0 0}$ in the total synthesis of (-)-podophyllotoxin (Scheme 37). ${ }^{64}$ Interestingly, $\mathrm{FeCl}_{3}$ was by far the best catalyst for conversion and diastereoselectivity among several acids assessed $\left(\mathrm{HBF}_{4}, \mathrm{AuCl}_{3}, \ldots\right)$ leading to the target compound in almost quantitative yield and excellent $\mathrm{dr}$.

The same iron catalyst was also successfully used in the coupling of 2,5-dimethylthiophene 102 with benzylic alcohol derivative 103 for the total synthesis of a prostaglandin EP4 receptor antagonist (Scheme 38$).{ }^{65}$

In 2010, Li described an interesting carbonylation-peroxidation of alkenes with aldehydes and hydroperoxides under 3 -component conditions. The obtained $\beta$-peroxyketones can then offer an easy access to $\alpha$-keto epoxides under basic conditions. ${ }^{66}$ The same authors used this method to prepare a key intermediate in the total synthesis of racemic clavilactones $\mathrm{A}$ and B: the $\beta$-peroxyketone $\mathbf{1 0 7}$ was prepared (60\%) and pyrrolidine treatment led to a syn epoxide $\mathbf{1 0 8}$ in very good yield $(87 \%)$ and $\mathrm{dr}(5: 1)$, which allowed them to obtain the key lactone fragment of clavilactones (Scheme 39). ${ }^{67}$

\section{Carbocyclisation}

During the 1980's, Takacs reported a powerful carbocyclisation proceeding through an intramolecular $\mathrm{Fe}(0)$-catalysed ene reaction between allylic ethers and diene moieties. ${ }^{\mathbf{6}}$ In these reactions, $\mathrm{Fe}(0)$ is generated in situ from $\mathrm{Fe}(\mathrm{acac})_{3}, \mathrm{Et}_{3} \mathrm{Al}$ as a reductant and a ligand, such as bipyridine (bipy) or a bisoxazoline (box). In 2002, this methodology was successfully applied to the diastereoselective preparation of the key cyclopentane core of (-)-gibboside in the total synthesis of this natural iridoid glucoside isolated from Patrinia gibbosa (Scheme 40). ${ }^{69}$ The reaction is very sensitive to impurities and the yield varied significantly (40-80\%), but always affording $\mathbf{1 1 0}$ as a single isomer.

The Pauson-Khand reaction (PK) is also a powerful tool for synthesizing cyclopentenone systems. ${ }^{70}$ While this $[2+2+1]$ carbocyclisation is generally performed with $\mathrm{Co}_{2}(\mathrm{CO})_{8}$ or $\mathrm{Mo}(\mathrm{CO})_{6}$ in stoichiometric amounts or as catalysts under $\mathrm{CO}$ atmosphere, some limitations are observed with highly 


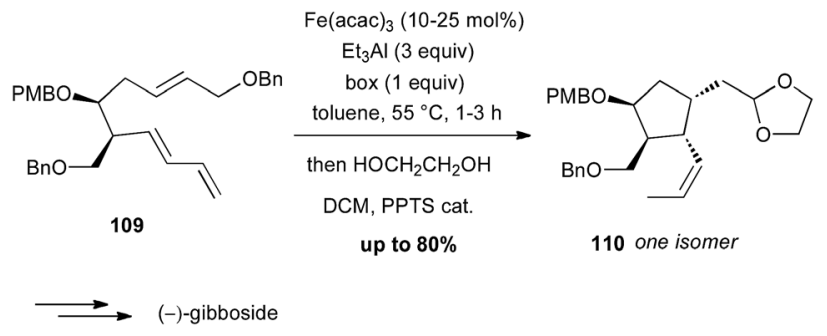

Scheme 40 Fe-catalysed enediene cyclisation for the synthesis of (-)-gibboside.

functionalised substrates. In contrast, Williams and Baik have shown that $\mathrm{Fe}_{2}(\mathrm{CO})_{9}$ (2.6 equiv.) is an efficient promoter for PK reaction between allenes and alkynes, which tolerates various functional groups. ${ }^{71}$ Shah and Williams have thus been able to perform the PK reaction on a substrate $\mathbf{1 1 1}$ bearing an oxazole moiety (61\% yield), affording a precursor 112 of (+)-ileabethoxazole (Scheme 41). ${ }^{72}$ Interestingly only the metal complex $\mathrm{Fe}_{2}(\mathrm{CO})_{9}$ was able to promote the carbocyclisation with this substrate.<smiles>C#CCC[C@H](C)C(=C=C)c1ocnc1[C@H](C)OC</smiles>

111

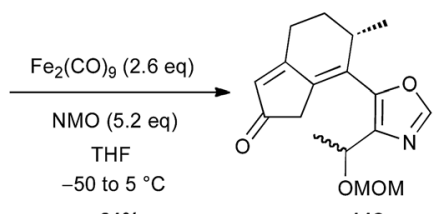

$61 \%$

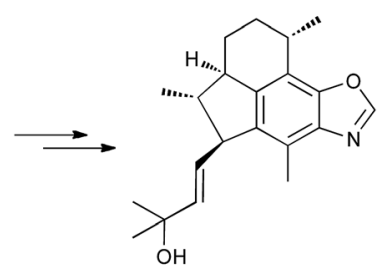

$(+)$-ileabethoxazole

Scheme 41 Fe-promoted Pauson-Khand reaction for the synthesis of $(+)$-ileabethoxazole.
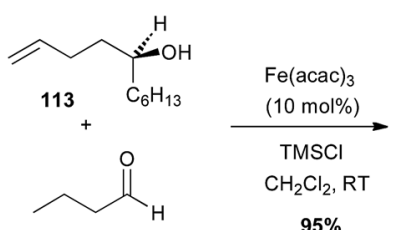

$95 \%$
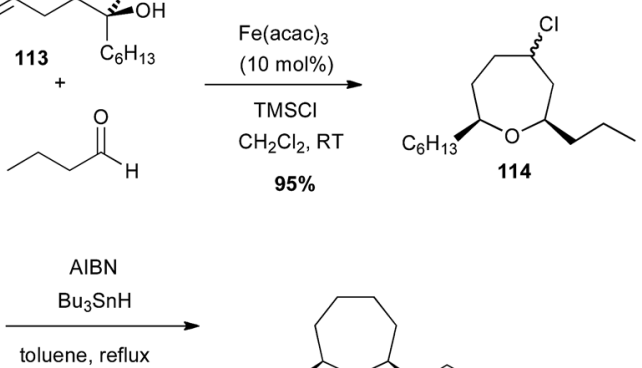

$90 \%$

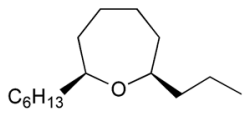

$(+)$-isolaurepan
Scheme 42 Fe-catalysed Prins cyclisation in the synthesis of (+)-isolaurepan.
Prins-type cyclisation generally occurs between homoallylic alcohols and an aldehyde under Brønsted or Lewis acidic conditions. In 2009, Padrón and Martín reported a catalytic Prins cyclisation from homoallyl amines or alcohols with catalytic iron(III) salt and stoichiometric TMSX leading to haloheterocycles. ${ }^{73}$ Thus, an enantiopure tertiary bis-homoallylic alcohol 113 reacted with butyraldehyde in presence of $\mathrm{Fe}(\mathrm{acac})_{3}$ (10 mol\%) and TMSCl (likely generating $\mathrm{FeCl}_{3}$ in situ) to afford the corresponding chlorooxepan 114 (95\% yield), which after reduction led to $(+)$-isolaurepan (Scheme 42). ${ }^{74}$

Analogous iron(III)-catalysed Prins-type cyclisation was also used to access an indene molecule 116 (79\% yield), which after demethylation and reduction afforded jungianol and its epimer (Scheme 43$).^{75}$

Oxidative coupling promoted by iron(III) chloride is a powerful method for $\mathrm{C}-\mathrm{C}$ bond formation between two arene moieties. ${ }^{76}$ Thus, iron-mediated oxidative cyclisation of bi-aryl compounds $\mathbf{1 1 7}$ has been used for the preparation of the phenanthrene core of several alkaloids, which were prepared in a few more steps (Scheme 44). ${ }^{77}$

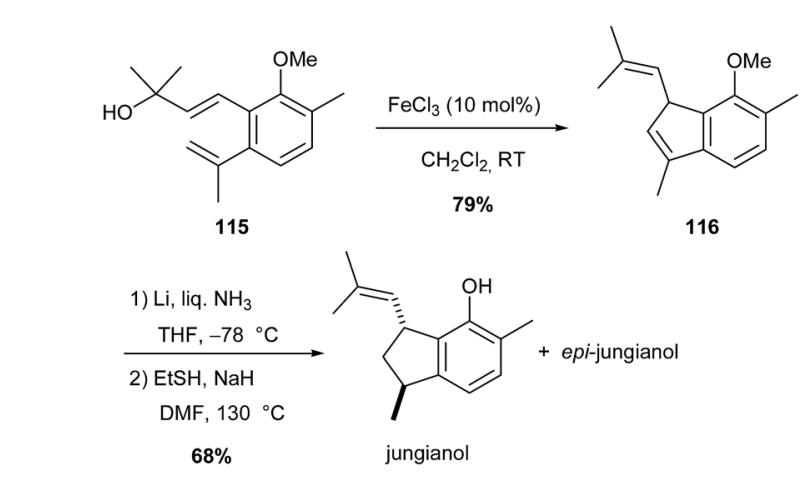

Scheme 43 Fe-catalysed Prins cyclisation in the synthesis of jungianol.

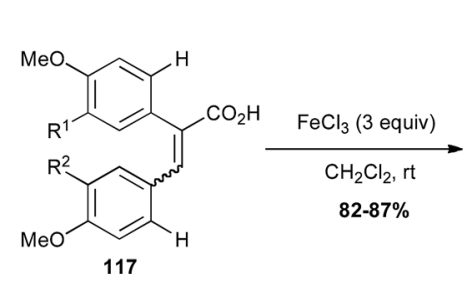<smiles>[R]c1cc2cc(C(=O)O)c3cc([R])c(OC)cc3c2cc1OC</smiles>

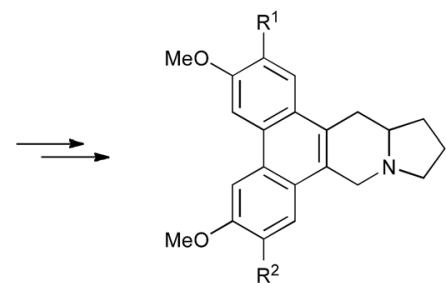

$\mathrm{R}^{1}=\mathrm{R}^{2}=\mathrm{OMe}:$ tylophorine $\mathrm{R}^{1}=\mathrm{H}, \mathrm{R}^{2}=\mathrm{OMe}:$ deoxytylophorine $\mathrm{R}^{1}=\mathrm{OMe}, \mathrm{R}^{2}=\mathrm{H}$ : antofine

Scheme 44 Fe-catalysed oxidative cyclisation of a biaryl for the synthesis of tylophorine, deoxytylophorine and antofine. 


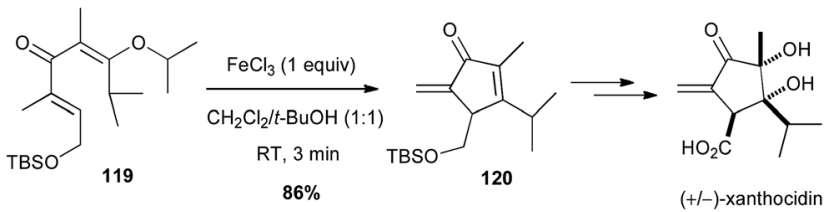

Scheme 45 Fe-promoted Nazarov cyclisation of a divinyl ketone for the synthesis of $(+/-)$-xanthocidin.

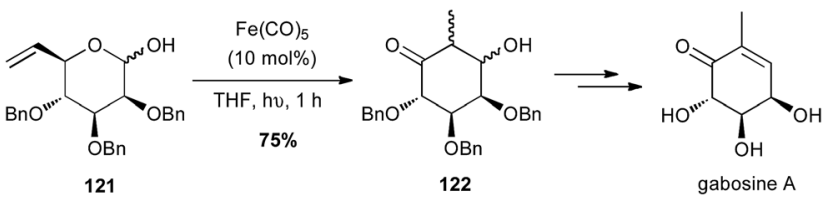

Scheme 46 Fe-promoted isomerisation-aldolisation of a vinyl pyranose for the synthesis of gabosine A.

A modified Nazarov reaction on a divinyl ketone 119 promoted by iron trichloride (1 equiv.) allowed Shindo to obtain the key $\alpha$-exo-methylene cyclopentadienone $\mathbf{1 2 0}$ in high yield $(86 \%)$, en route to the total synthesis of $(+/-)$-xanthocidin, an antibiotic isolated from Streptomyces xanthocidicus (Scheme 45$)^{78}$

Grée reported in 2011 that an intramolecular tandem $\mathrm{Fe}(\mathrm{CO})_{5}$-catalysed isomerisation-aldolisation reaction starting from vinyl pyranose $\mathbf{1 2 1}$ allowed a short and elegant synthesis of natural products from the gabosine family (Scheme 46). ${ }^{79}$

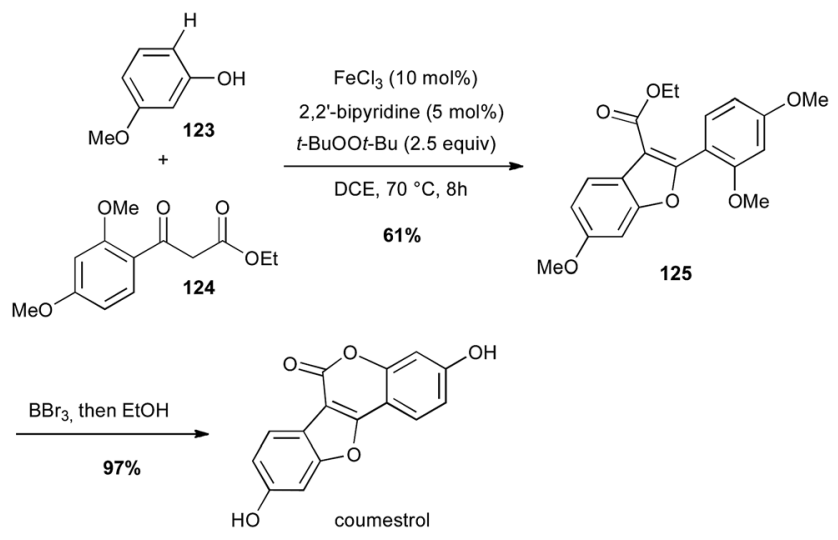

Scheme 47 Fe-catalysed coupling of a phenol with $\beta$-keto ester for the synthesis of coumestrol.

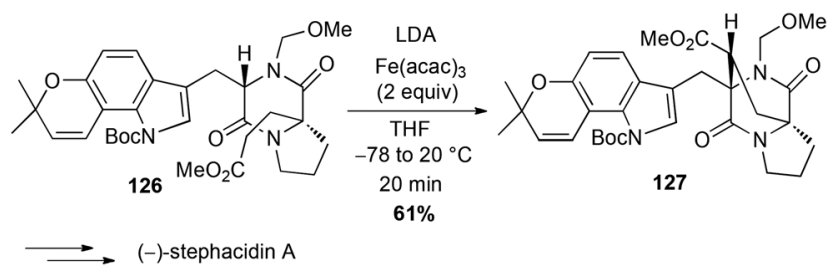

Scheme 48 Fe-catalysed oxidative coupling for the synthesis of (-)-stephacidin A.

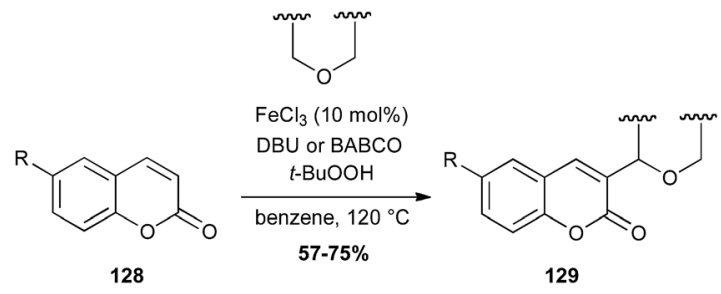

Scheme 49 Fe-catalysed coupling of coumarins with ethers.

\section{5. $\mathrm{C}-\mathrm{H}$ activation}

Iron has also been used for direct $\mathrm{C}-\mathrm{H}$ activation. For instance, cross-dehydrogenative coupling (CDC) between $\mathrm{sp}^{2} \mathrm{C}-\mathrm{H}$ bond of a phenol $\mathbf{1 2 3}$ in the presence of a $\beta$-keto ester $\mathbf{1 2 4}$ and $\mathrm{FeCl}_{3}$ allowed the preparation in a gram-scale of the benzofuran core of coumestrol, a natural estrogenic analogue, in good yield (Scheme 47). ${ }^{80}$

In 2006, Baran reported a formal intramolecular coupling between two $\mathrm{sp}^{3} \mathrm{C}-\mathrm{H}$ bonds albeit the reaction goes through oxidative heterocoupling of two types of enolates. Enolates are generated in presence of LDA and the coupling takes place in presence of an oxidant, among which $\mathrm{Fe}(\mathrm{acac})_{3}$ (2 equiv.) proved to be very efficient ( $61 \%$ yield of 127 ). Thus, this method allowed the preparation in a gram-scale of the polycyclic core of (-)-stephacidin A, a natural estrogenic analogue (Scheme 48). ${ }^{81}$

Coumarin is a fragrant compound found in many plants. In 2015, an interesting radical coupling between coumarins 128 and ethers catalyzed by iron chloride in presence of TBHP has been described. This reaction allows the formation of a C-C bond between an $\mathrm{sp}^{2}$ carbon of the coumarin and the carbon in $\alpha$-position of the ether (Scheme 49). ${ }^{82}$

\section{Conclusions}

Iron-catalysed reactions are nowadays-key tools in the total synthesis of natural products and pharmacologically important chemical entities. While the cross-coupling reaction between Grignard reagents and numerous electrophiles is well documented and constitutes the most visible facet, iron catalysis is only at the dawn of its development. Innovative and powerful methodology, such as Fe-catalysed $\mathrm{C}-\mathrm{H}$ activation, is still an under-explored field, which will become shortly a source of new applications, especially for the large-scale preparation of highly functionalised molecules. Moreover, the number of enantioselective transformations with iron is still low compared to other metals and such methodologies are definitely required in total synthesis. Attractiveness of iron salts relies for sure on their cost and their non-toxic property, but efficiency and selectivity observed in these chemical transformations are also the driving force of the efforts brought in these studies.

\section{Acknowledgements}

J. L. is grateful to Labex SynOrg (ANR-11-LABX-0029), the Région Haute-Normandie and the European France (Manche) - 
England cross-border cooperation program INTERREG IV A "AI-CHEM CHANNEL" and co-financed by ERDF for financial support. Labex LERMIT (ANR-10-LABX-33) is acknowledged for financial support (BF).

\section{References}

1 P. Enghag, Encyclopedia of the elements technical data, history, processing, applications, Wiley-VCH, Weinheim, 2004.

2 J. W. Morgan and E. Anders, Proc. Natl. Acad. Sci. U. S. A., 1980, 77, 6973-6977.

3 G. M. Yee and W. B. Tolman, in Sustaining Life on Planet Earth: Metalloenzymes Mastering Dioxygen and Other Chewy Gases, ed. P. M. H. Kroneck and M. E. S. Torres, Springer International Publishing, 2015, pp. 131-204.

4 M. Rueping and B. J. Nachtsheim, Beilstein J. Org. Chem., 2010, 6, 6.

5 C. Bolm, J. Legros, J. Le Paih and L. Zani, Chem. Rev., 2004, 104, 6217-6254.

6 I. Bauer and H.-J. Knölker, Chem. Rev., 2015, 115, 3170-3387.

7 B. Plietker, Iron catalysis in organic chemistry: reactions and applications, Wiley-VCH, Weinheim, 2008.

8 A. Fürstner, Angew. Chem., Int. Ed., 2009, 48, 1364-1367.

9 Metal-Catalyzed Cross-Coupling Reactions, ed. A. de Meijere and F. Diederich, Wiley-VCH Verlag GmbH, Weinheim, Germany, 2004.

10 M. Tamura and J. Kochi, Synthesis, 1971, 303-305.

11 M. Tamura and J. K. Kochi, J. Am. Chem. Soc., 1971, 93, 14871489.

12 G. Cahiez and H. Avedissian, Synthesis, 1998, 1199-1205.

13 B. Bogdanović and M. Schwickardi, Angew. Chem., Int. Ed., 2000, 39, 4610-4612.

14 A. Fürstner, H. Krause and C. W. Lehmann, Angew. Chem., Int. Ed., 2006, 45, 440-444.

15 A. Fürstner, R. Martin, H. Krause, G. Seidel, R. Goddard and C. W. Lehmann, J. Am. Chem. Soc., 2008, 130, 8773-8787.

16 Q. Ren, S. Guan, F. Jiang and J. Fang, J. Phys. Chem. A, 2013, 117, 756-764.

17 R. B. Bedford, P. B. Brenner, E. Carter, P. M. Cogswell, M. F. Haddow, J. N. Harvey, D. M. Murphy, J. Nunn and C. H. Woodall, Angew. Chem., Int. Ed., 2014, 53, 1804-1808.

18 A. Hedström, Z. Izakian, I. Vreto, C.-J. Wallentin and P.-O. Norrby, Chem.-Eur. J., 2015, 21, 5946-5953.

19 R. B. Bedford, Acc. Chem. Res., 2015, 48, 1485-1493.

20 B. D. Sherry and A. Fürstner, Acc. Chem. Res., 2008, 41, 15001511.

21 W. M. Czaplik, M. Mayer, S. Grupe and A. J. von Wangelin, Pure Appl. Chem., 2010, 82, 1545-1553.

22 J. Defretin, C. Gleye, D. Cortes, X. Franck, R. Hocquemiller and B. Figadere, Lett. Org. Chem., 2004, 1, 316-322.

23 A. A. Camacho-Davila, Synth. Commun., 2008, 38, 3823-3833.

24 D. Castagnolo and M. Botta, Eur. J. Org. Chem., 2010, 2010, 3224-3228.

25 N. Tewari, N. Maheshwari, R. Medhane, H. Nizar and M. Prasad, Org. Process Res. Dev., 2012, 16, 1566-1568.

26 R. N. Shakhmaev, A. S. Sunagatullina and V. V. Zorin, Russ. J. Org. Chem., 2014, 50, 322-331.
27 B. Scheiper, M. Bonnekessel, H. Krause and A. Fürstner, J. Org. Chem., 2004, 69, 3943-3949.

28 A. Fürstner and P. Hannen, Chem.-Eur. J., 2006, 12, 30063019.

29 A. Hamajima and M. Isobe, Org. Lett., 2006, 8, 1205-1208.

30 J. Boukouvalas, V. Albert, R. P. Loach and R. LafleurLambert, Tetrahedron, 2012, 68, 9592-9597.

31 Y. Liang, X. Jiang and Z.-X. Yu, Chem. Commun., 2011, 47, 6659-6661.

32 K. C. Nicolaou, Y.-P. Sun, H. Korman and D. Sarlah, Angew. Chem., Int. Ed., 2010, 49, 5875-5878.

33 A. Fürstner and A. Schlecker, Chem.-Eur. J., 2008, 14, 91819191.

34 G. Cahiez, O. Gager and V. Habiak, Synthesis, 2008, 26362644.

35 G. Cahiez, V. Habiak and O. Gager, Org. Lett., 2008, 10, 23892392.

36 J. R. Scheerer, J. F. Lawrence, G. C. Wang and D. A. Evans, J. Am. Chem. Soc., 2007, 129, 8968-8969.

37 M. A. Fakhfakh, X. Franck, R. Hocquemiller and B. Figadère, J. Organomet. Chem., 2001, 624, 131-135.

38 M. Dos Santos, X. Franck, R. Hocquemiller, B. Figadere, J.-F. Peyrat, O. Provot, J.-D. Brion and M. Alami, Synlett, 2004, 2697-2700.

39 K. Lehr, S. Schulthoff, Y. Ueda, R. Mariz, L. Leseurre, B. Gabor and A. Fürstner, Chem.-Eur. J., 2015, 21, 219-227.

40 M. Fuchs and A. Fürstner, Angew. Chem., Int. Ed., 2015, 54, 3978-3982.

41 L. K. Ottesen, F. Ek and R. Olsson, Org. Lett., 2006, 8, 17711773.

42 A. Fürstner and A. Leitner, Angew. Chem., Int. Ed., 2002, 41, 609-612.

43 G. Seidel, D. Laurich and A. Fürstner, J. Org. Chem., 2004, 69, 3950-3952.

44 A. Fürstner and A. Leitner, Angew. Chem., Int. Ed., 2003, 42, 308-311.

45 B. Scheiper, F. Glorius, A. Leitner and A. Fürstner, Proc. Natl. Acad. Sci. U. S. A., 2004, 101, 11960-11965.

46 U. Groenhagen, M. Maczka, J. S. Dickschat and S. Schulz, Beilstein J. Org. Chem., 2014, 10, 1421-1432.

47 C. Risatti, K. J. Natalie, Z. Shi and D. A. Conlon, Org. Process Res. Dev., 2013, 17, 257-264.

48 S. M. Andersen, M. Bollmark, R. Berg, C. Fredriksson, S. Karlsson, C. Liljeholm and H. Sörensen, Org. Process Res. Dev., 2014, 18, 952-959.

49 F. Bartoccini, G. Piersanti, S. Armaroli, A. Cerri and W. Cabri, Tetrahedron Lett., 2014, 55, 1376-1378.

50 A. Guerinot, G. Lepesqueux, S. Sable, S. Reymond and J. Cossy, J. Org. Chem., 2010, 75, 5151-5163.

51 C. Gregg, C. Gunawan, A. W. Y. Ng, S. Wimala, S. Wickremasinghe and M. A. Rizzacasa, Org. Lett., 2013, 15, 516-519.

52 T. Lam and N. I. Totah, Tetrahedron Lett., 2015, 56, 33493352 .

53 C. Bensoussan, N. Rival, G. Hanquet, F. Colobert, S. Reymond and J. Cossy, Tetrahedron, 2013, 69, 7759-7770. 
54 K. Yamada, T. Sato, M. Hosoi, Y. Yamamoto and K. Tomioka, Chem. Pharm. Bull., 2010, 58, 1511-1516.

55 C. W. Cheung, P. Ren and X. Hu, Org. Lett., 2014, 16, 25662569.

56 M. Jin, L. Adak and M. Nakamura, J. Am. Chem. Soc., 2015, 137, 7128-7134.

57 V. Fiandanese, G. Marchese, V. Martina and L. Ronzini, Tetrahedron Lett., 1984, 25, 4805-4808.

58 A. Fürstner, D. De Souza, L. Parra-Rapado and J. T. Jensen, Angew. Chem., Int. Ed., 2003, 42, 5358-5360.

59 K. Lehr and A. Fürstner, Tetrahedron, 2012, 68, 7695-7700.

60 O. Lepage, E. Kattnig and A. Fürstner, J. Am. Chem. Soc., 2004, 126, 15970-15971.

61 A. Fürstner, E. Kattnig and O. Lepage, J. Am. Chem. Soc., 2006, 128, 9194-9204.

62 T. Kang, S. B. Song, W.-Y. Kim, B. G. Kim and H.-Y. Lee, J. Am. Chem. Soc., 2014, 136, 10274-10276.

63 C.-L. Sun and A. Fürstner, Angew. Chem., Int. Ed., 2013, 52, 13071-13075.

64 D. Stadler and T. Bach, Angew. Chem., Int. Ed., 2008, 47, 7557-7559.

65 D. Gauvreau, S. J. Dolman, G. Hughes, P. D. O'Shea and I. W. Davies, J. Org. Chem., 2010, 75, 4078-4085.

66 W. Liu, Y. Li, K. Liu and Z. Li, J. Am. Chem. Soc., 2011, 133, 10756-10759.

67 L. Lv, B. Shen and Z. Li, Angew. Chem., Int. Ed., 2014, 53, 4164-4167.

68 J. M. Takacs and L. G. Anderson, J. Am. Chem. Soc., 1987, 109, 2200-2202.
69 J. M. Takacs, S. Vayalakkada, S. J. Mehrman and C. L. Kingsbury, Tetrahedron Lett., 2002, 43, 8417-8420.

70 K. M. Brummond and J. L. Kent, Tetrahedron, 2000, 56, 32633283.

71 D. R. Williams, A. A. Shah, S. Mazumder and M.-H. Baik, Chem. Sci., 2013, 4, 238-247.

72 D. R. Williams and A. A. Shah, J. Am. Chem. Soc., 2014, 136, 8829-8836.

73 P. O. Miranda, R. M. Carballo, V. S. Martín and J. I. Padrón, Org. Lett., 2009, 11, 357-360.

74 M. A. Purino, M. A. Ramírez, A. H. Daranas, V. S. Martín and J. I. Padrón, Org. Lett., 2012, 14, 5904-5907.

75 D. H. Dethe and G. Murhade, Org. Lett., 2013, 15, 429-431. 76 A. A. O. Sarhan and C. Bolm, Chem. Soc.Rev., 2009, 38, 2730.

77 K.-L. Wang, M.-Y. Lü, Q.-M. Wang and R.-Q. Huang, Tetrahedron, 2008, 64, 7504-7510.

78 K. Yaji and M. Shindo, Tetrahedron, 2010, 66, 9808-9813.

79 D. H. Mac, R. Samineni, A. Sattar, S. Chandrasekhar, J. S. Yadav and R. Grée, Tetrahedron, 2011, 67, 9305-9310.

80 U. A. Kshirsagar, R. Parnes, H. Goldshtein, R. Ofir, R. Zarivach and D. Pappo, Chem.-Eur. J., 2013, 19, 1357513583.

81 P. S. Baran, B. D. Hafensteiner, N. B. Ambhaikar, C. A. Guerrero and J. D. Gallagher, J. Am. Chem. Soc., 2006, 128, 8678-8693.

82 B. Niu, W. Zhao, Y. Ding, Z. Bian, C. U. Pittman, A. Zhou and H. Ge, J. Org. Chem., 2015, 80, 7251-7257. 